\title{
Comparison of Different Stenting Techniques of Coronary Bifurcation Lesions: A Network Meta-Analysis of 7601 Patients
}

\section{Type}

Research paper

\section{Keywords}

crush, Coronary bifurcations lesions (CBL), DKcrush, culotte, T and protrusion (TAP). Provisional, Major adverse cardiovascular events (MACE)

\begin{abstract}
Introduction

Intervention on coronary bifurcations lesions $(\mathrm{CBL})$ is challenging. While provisional side branch (PS) stenting is the recommended method in most cases, there is no consensus on the preferred 2-stent technique.

\section{Material and methods}

We performed a network meta-analysis including randomized controlled trials (RCT) and observational studies comparing stenting techniques in CBL with reported clinical outcomes. A mixed treatment comparison model generation was performed to compare culotte, $T$ and protrusion (TAP), crush and provisional techniques.
\end{abstract}

\section{Results}

We included 14 RCT and 14 observational studies comprising 7,601 patients among whom 2,516 were treated with PS, 792 with TAP, 1,493 with culotte and 2,808 with crush. A Bayesian network meta-analysis showed a significant rate reduction of major adverse cardiovascular events $(\mathrm{OR}=0.73$; $95 \% \mathrm{Cl} 0.52-0.99)$ and a trend for reduction in lesion revascularization $(\mathrm{OR}=0.72 ; 95 \% \mathrm{Cl} 0.48-1.11)$ and myocardial infarction $(\mathrm{OR}=0.62 ; 95 \% \mathrm{Cl} 0.3-1.08)$ with the crush technique, mainly driven by the double kissing (DK) crush, compared with all other stenting techniques. Other clinical outcomes, including mortality and stent thrombosis (ST) did not differ significantly between methods.

\section{Conclusions}

The crush technique, and especially DKcrush, is associated with improved outcomes compared to culotte, $T$ and protrusion (TAP) and provisional techniques for CBL treatment. Further research is required to determine the optimal stenting technique for $\mathrm{CBL}$. 


\begin{abstract}
Background: Intervention on coronary bifurcations lesions (CBL) is challenging. While provisional side branch (PS) stenting is the recommended method in most cases, there is no consensus on the preferred 2-stent technique.

Methods: We performed a network meta-analysis including randomized controlled trials (RCT) and observational studies comparing stenting techniques in CBL with reported clinical outcomes. A mixed treatment comparison model generation was performed to compare culotte, $\mathrm{T}$ and protrusion (TAP), crush and provisional techniques.
\end{abstract}

Results: We included $14 \mathrm{RCT}$ and 14 observational studies comprising 7,601 patients among whom 2,516 were treated with PS, 792 with TAP, 1,493 with culotte and 2,808 with crush. A Bayesian network meta-analysis showed a significant rate reduction of major adverse cardiovascular events $(\mathrm{OR}=0.73 ; 95 \% \mathrm{CI} 0.52-0.99)$ and a trend for reduction in lesion revascularization $(\mathrm{OR}=0.72 ; 95 \% \mathrm{CI} 0.48-1.11)$ and myocardial infarction $(\mathrm{OR}=0.62 ; 95 \% \mathrm{CI}$ 0.3-1.08) with the crush technique, mainly driven by the double kissing (DK) crush, compared with all other stenting techniques. Other clinical outcomes, including mortality and stent thrombosis (ST) did not differ significantly between methods.

Conclusion: The crush technique, and especially DKcrush, is associated with improved outcomes compared to culotte T and protrusion (TAP) and provisional techniques for CBL treatment. Further research is required to determine the optimal stenting technique for CBL. 


\section{Introduction}

Coronary bifurcation lesions (CBL) account for $15-20 \%$ of all percutaneous coronary interventions (PCI) and constitute a major challenge for interventional cardiologists ${ }^{1}$ in terms of both procedural success and long-term major adverse cardiac events (MACE) ${ }^{2,3}$. Based on data from multiple randomized controlled trials (RCT) and registries, current guidelines advocate the use of provisional side branch (SB) stenting for the majority of $\mathrm{CBL}^{3}$. However, an upfront double stent technique should be considered for complex CBL (long side branch lesions, difficult side branch access or high risk of side branch compromise) since a provisional strategy may potentially lead to acute or long-term occlusion of a significant side branch. In these cases, which account for 5 to $25 \%$ of CBL, a 2-stent technique may be needed for optimal results ${ }^{3}$. Several dual-stenting techniques are recommended, including reverse provisional stenting, T-stenting and small protrusion (TAP) in which a second stent is being advanced through the struts of the MB stent into the SB and deployed with slight (1-2mm) protrusion into the MB, then both the MB balloon ant the SB stent balloon are simultaneously inflated. Culotte technique in which 2 stents are deployed in tandem, from the main vessel into each branch with strut opening to each branch by kissing balloon inflation leaving the proximal main vessel covered with two overlapped stents, and crush modification including mini-crush and double kissing crush (DK crush) which consists of stenting from the main vessel into the SB, balloon crushing from the MB, stenting from the main vessel into the MB and final kissing balloon inflation. The DKcrush modification is performed with a 2 kissing 
balloon inflations, both prior and following the second stent deployment ${ }^{3,4}$.

Nevertheless, due to the anatomical and technical complexity of these lesions and methods, treatment results may be affected by several factors such as the selected double stenting technique, operator's experience and the use of intracoronary imaging during the $\mathrm{PCI}^{5,6}$. Therefore, the optimal 2-stent technique for CBL remains controversial. Accordingly, we performed a network meta-analysis of RCT and observational studies comparing the clinical outcomes of various 2 -stent techniques with provisional stenting in CBL.

\section{Methods}

The primary objective of this network meta-analysis was to compare the various 2 stents techniques for CBL, with a common comparator of a provisional technique, with regards to clinical outcomes including MACE defined in most studies as mortality, myocardial infarction and target vessel or lesion revascularization, target lesion revascularization (TLR), all-cause mortality, myocardial infarction (MI) and stent thrombosis (ST). Clinical outcomes and events rate are based on the definitions given and the reported incidents in each study. We included the recommended techniques such as crush, culotte, and TAP, but not simultaneous kissing stents which is no longer recommended (EBC statement). We included in the crush group all methods such as mini-crush, classic crush, and DK crush since the concept of the result was similar. Nevertheless, to assess the impact of DKcrush, we performed a separate analysis with DKcrush group as an independent group from other crush techniques. Two independent investigators (EK and LH) had systematically screened (January 2020) MEDLINE/PubMed for titles and abstracts containing the terms coronary bifurcation " OR " crush stenting" OR" provisional stenting" OR "culotte 
stenting", reviewed the full-text articles and determined their eligibility. Included in the meta-analysis were RCTs and observational studies, comparing at least two of the listed PCI techniques for CBL with available clinical follow-up separately for each technique. Studies with inadequate outcome data, duplication of data and those available only in abstract form were excluded from the analysis. Data was abstracted by additional two investigators (OB and $A D)$ in accordance with the Preferred Reporting Items for Systematic Reviews and Meta-Analyses (PRISMA) and Metaanalysis Of Observational Studies in Epidemiology (MOOSE) guidelines ${ }^{7,8}$ The type of study, year of publication, time of follow up, treatment allocation and stenting technique, patients' age, gender, co-morbidities, left ventricular ejection fraction (LVEF) and outcome data for TLR, MACE, MI, ST and all-cause mortality at the longest available follow-up were extracted and recorded when available. We accepted the studies definitions for adverse events.

\section{Statistical analysis}

Dichotomous variables are expressed as percentages and continuous variables as mean \pm standard deviation or median + IQR (interquartile range) based on normal distribution. To compare directly and indirectly between the CBL interventional techniques: provisional, crash, culotte, and TAP we used a mixed treatment comparison model generation performed by GeMTC 0.14.3 software (GeMTC, http://drugis.org/software/r-packages/gemtc). Bayesian hierarchical random-effects model with directed acyclic graph model for general-purpose Markov chain Monte Carlo analysis was performed with 50,000 tuning iterations and 100,000 simulation iterations. Data is presented as odds ratios (OR) and 95\% credible intervals (CrI). Convergence was appraised graphically according to Gelman and Rubin ${ }^{9}$. Data from a 
consistency model are presented, and the direction of findings were confirmed with an inconsistency model to serve as a sensitivity analysis. Additional sensitivity analysis was performed with removal of one study at a time to confirm directionality and magnitude of findings. Statistical significance was defined as a P-value $<0.05$.

\section{Results}

We screened and reviewed a total of 4,005 MEDLINE citations using the previously defined search terms. 212 abstracts which met the inclusion/exclusion criteria were evaluated, and from them 76 full-text publications were reviewed in detail. Finally, we entered 28 studies in the meta-analysis, including 14 RCTs ${ }^{10,11,20-}$ ${ }^{23,12-19}$ and 14 observational studies ${ }^{24,25,34-37,26-33}$. The study flow chart is shown in

\section{Figure 1.}

Characteristics of studies included in the meta-analysis are presented in Table $\mathbf{1 .}$ Among the 7,601 patients with CBL identified from the included articles, 1,493 were treated with culotte, 2,808 with crush, 792 with TAP and 2,516 with provisional stenting. Figure 2 represents the number of patients treated by each BCL technique. Mean follow-up was 28.6 months. Patients baseline characteristics are shown in Table 2. Mean age was $65.9_{ \pm} 9.9$ years. Men comprised $76.3 \%$ of the population, $33 \%$ were smokers and $28 \%$ had diabetes mellitus. Prior MI was present in 24\%, $28 \%$ of patients had undergone previous PCI and $4.8 \%$ had prior coronary artery bypass

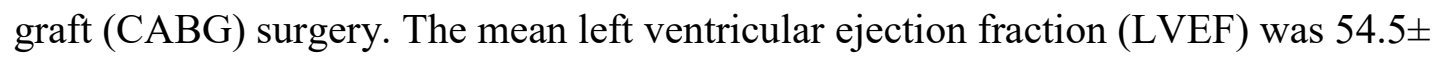
12\%. Angiographic and procedural characteristics are shown in Table 3. True bifurcation lesions were present in over $90 \%$ of the patients, left main lesions were included in 18 studies and were recorded in 3,108 patients, kissing balloon inflation 
(KBI) was performed in $81 \%$ of CBL and intracoronary imaging was used in 13 studies and 2,011 patients.

The network plot for MACE with and without DKcrush is presented in figure 3. The Bayesian network meta-analysis demonstrated the superiority of the crush technique, but not culotte and TAP, over provisional stenting in reduction of MACE $(\mathrm{OR}=0.73$; 95\%CI 0.52-0.99) (Figure 4). This was mostly driven by lower TLR and MI rates, while mortality and ST did not differ significantly between stenting methods, possibly due to the low event rate and lack of statistical power.

Rankings of therapies according to the probability of being the best, second, third and fourth based on the Bayesian network meta-analysis revealed similar results with the crush technique as a leading 2-stent treatment modality in all outcomes, as shown in Figure 5

When differentiating between double kissing crush (DKcrush) and other crush methods, the results indicate that the crush superiority was driven by the DKcrush technique (Figure 6). Ranking of treatment showed similar findings indicating that it is DKcrush which results in improved clinical outcome for patients with bifurcation lesions requiring 2 stents (figure 7).

When limiting the analysis to RCTs, there was no statistically significant difference in any of the stated endpoints between provisional stenting and the various 2 stent techniques, although there was a trend favoring the crush technique over provisional stenting in terms of TLR (supplementary figures 1-4). Similar results were found when analyzing only studies of left main bifurcation disease, with a trend for superiority of the crush technique over other 2 stent techniques, especially over 
culotte in terms of TLR and MACE (supplementary figures 5-8). When excluding a single study at a time there was not significant difference in the results.

\section{Discussion}

The main finding of the largest meta-analysis so far of separately grouped CBL stenting techniques, is that the crush technique provides superior clinical outcomes as compared to any other technique in the treatment of CBL. This superiority in terms of MACE is driven mostly by lower rates of TLR and MI and by use of the DKcrush method. Our finding is supported by the similar results observed in various analyses, including only left main studies or RCTs. There were no significant differences between techniques in terms of mortality and stent thrombosis The impact of the method used may have been less pronounced for these clinical outcomes due to low event rates and lack of statistical power.

The main drawback of the crush technique and in particular DKcrush, is the commitment to 2 stents deployment. Therefore, this approach cannot be used as a bail-out for provisional stenting, in contrast to the culotte and TAP techniques. According to our results crush technique with the preference for DKcrush is to be used mainly in cases where 2 stents are needed upfront, such as the presence of a severe long lesion in the SB, as suggested by the European Bifurcation Club consensus document ${ }^{38}$.

Extensive published data exist regarding the optimal technique for CBL. However, besides the general recommendation for provisional stenting that was shown to be superior to 2 -stent techniques ${ }^{39}$, up until recently there were no recommendations regarding which 2-stent technique should be employed. The 
DKCRUSH trials showed superiority of this technique over culotte and classic crush technique $^{40}$ and even provisional stenting ${ }^{13,15,41}$. This can result from facilitating easier SB access and higher rate of KBI, which subsequently preserves the carina covering by improved SB and MB stents apposition and reduces stent malformation at the bifurcation ${ }^{42}$. A recently published network meta-analysis by Di-Gioia et al including only RCTs showed similar results to our findings ${ }^{43}$. However, this metaanalysis included several trials which combined several two stenting techniques into a single group, comprising almost 1,500 patients. A third of the crush stenting group in the British Bifurcation Coronary study ${ }^{44}$ included patients who underwent other techniques and in the Nordic Bifurcation Study ${ }^{45}$ it was half of the crush group. Likewise, the culotte group in the Nordic Bifurcation Study $\mathrm{IV}^{46}$ included $35 \%$ of patients with different techniques. In the present analysis, the largest one so far, we included only reported data on individual stenting techniques in RCT's along with observational trials for the main analysis along with a sensitivity analysis for RCTs only.

Many additional factors may impact patient outcome following CBL stenting other than the technique used, including clinical, demographic, anatomical and physiological features, as well as adjunctive procedural techniques, operator experience and adjunctive pharmacotherapy.

It has been previously shown that risk scores ${ }^{47}$ and comorbidities such as diabetes $^{48}$ increase the risk of adverse events in patients with CBL treated percutaneously. The Medina classification and involvement of the $\mathrm{SB}^{49-52}$ are important predictors of procedural success and long-term adverse events, but are on occasion difficult to assess due to the subjectivity of visual assessment and the complexity of the three dimensional anatomy depicted on a two dimensional screen ${ }^{53}$. 
Intracoronary imaging can clarify lesion characteristics and has been shown to improve clinical outcome of patients undergoing $\mathrm{PCI}^{54,55}$, however, its utilization rate and methods varies significantly from current recommendations ${ }^{56,57}$. Arguably, the most important issue in treating bifurcation lesions is operator's proficiency. Experienced operators were shown to achieve better outcomes than less experienced ones when performing PCI of the LM, the most important coronary bifurcation ${ }^{58}$. Hence, it could be that operator preference and familiarity with each technique is the most important determinant of outcome, possibly even more than the technique itself. Therefore, when choosing the appropriate stenting technique in CBL, all of the above parameters should be taken into consideration, including utilization of correct work projections that clarify the CBL, use of advanced physiological and imaging tools such as pressure wires and intravascular imaging and operator skill with the various techniques in different clinical scenarios. In addition, the development of dedicated CBL stents with various mechanisms may further improve the treatment of these lesions ${ }^{59-61}$

Our study has several limitations. First, the meta-analysis includes both RCTs and observational studies, which may have selection biases as there could be additional confounders that could impact the results and were not necessarily reported. Nonetheless, a sensitivity analysis including only randomized controlled trials showed an overall similar result in all outcomes. Second, the bifurcation classification and lesion complexity vary from study to study and are not necessarily adjudicated, especially considering the low usage rate of intracoronary imaging. Third, the reported outcome definitions vary between studies and therefor impact the total event rate with each technique. 
In conclusion, our study demonstrates that among the various 2 -stent techniques, crush might be associated with potentially better outcomes compared with culotte and TAP, mostly driven by the reduction of MACE with the DKcrush method. Further research should clarify the role of potential factors, such as intracoronary imaging and physiology and operator's experience, that may impact the procedural success and long-term outcome with the various techniques. 


\section{References}

1. Lassen JF, Holm NR, Stankovic G, et al. Percutaneous coronary intervention for coronary bifurcation disease: consensus from the first 10 years of the European Bifurcation Club meetings. EuroIntervention. 2014;10(5):545-560. doi:10.4244/EIJV10I5A97

2. Louvard Y, Thomas M, Dzavik V, et al. Classification of coronary artery bifurcation lesions and treatments: Time for a consensus! Catheter Cardiovasc Interv. 2008;71(2):175-183. doi:10.1002/ccd.21314

3. Lassen JF, Burzotta F, Banning AP, et al. Percutaneous coronary intervention for the left main stem and other bifurcation lesions: 12th consensus document from the European Bifurcation Club. EuroIntervention. 2018;13(13):15401553. doi:10.4244/EIJ-D-17-00622

4. De Luca L. Percutaneous Treatment of Coronary Bifurcation Lesions: Is Simplicity the Ultimate Sophistication? Circ Cardiovasc Interv. 2016;9(9). doi:10.1161/CIRCINTERVENTIONS.116.004328

5. Xu L, Zhao H, Qiu J, et al. The Different Effects of BMI and WC on Organ Damage in Patients from a Cardiac Rehabilitation Program after Acute Coronary Syndrome. Biomed Res Int. 2015;2015:942695. doi:10.1155/2015/942695

6. $\mathrm{Xu} \mathrm{L}$, Huang X, Ma J, et al. Value of three-dimensional strain parameters for 
predicting left ventricular remodeling after ST-elevation myocardial infarction. Int J Cardiovasc Imaging. 2017;33(5):663-673. doi:10.1007/s10554-016-10533

7. Hutton B, Salanti G, Caldwell DM, et al. The PRISMA extension statement for reporting of systematic reviews incorporating network meta-analyses of health care interventions: checklist and explanations. Ann Intern Med. 2015;162(11):777-784. doi:10.7326/M14-2385

8. Stroup DF, Berlin JA, Morton SC, et al. Meta-analysis of observational studies in epidemiology: A proposal for reporting. J Am Med Assoc. 2000;283(15):2008-2012. doi:10.1001/jama.283.15.2008

9. Gelman A, Rubin DB. Markov chain Monte Carlo methods in biostatistics. Stat Methods Med Res. 1996;5(4):339-355. doi:10.1177/096228029600500402

10. Hildick-Smith D, Behan MW, Lassen JF, et al. The EBC TWO Study (European Bifurcation Coronary TWO): A Randomized Comparison of Provisional T-Stenting Versus a Systematic 2 Stent Culotte Strategy in Large Caliber True Bifurcations. Circ Cardiovasc Interv. 2016;9(9). doi:10.1161/CIRCINTERVENTIONS.115.003643

11. Ferenc M, Ayoub M, Büttner HJ, et al. Long-term outcomes of routine versus provisional T-stenting for de novo coronary bifurcation lesions: Five-year results of the Bifurcations Bad Krozingen i study. EuroIntervention. 2015;11(8):856-859. doi:10.4244/EIJV11I8A175

12. Colombo A, Bramucci E, Saccà S, et al. Randomized study of the crush technique versus provisional side-branch stenting in true coronary bifurcations: The CACTUS (Coronary bifurcations: Application of the Crushing Technique 
Using Sirolimus-eluting stents) study. Circulation. 2009;119(1):71-78. doi:10.1161/CIRCULATIONAHA.108.808402

13. Chen S-L, Santoso T, Zhang J-J, et al. Clinical Outcome of Double Kissing Crush Versus Provisional Stenting of Coronary Artery Bifurcation Lesions: The 5-Year Follow-Up Results From a Randomized and Multicenter DKCRUSH-II Study (Randomized Study on Double Kissing Crush Technique Versus Provisi. Circ Cardiovasc Interv. 2017;10(2):e004497. doi:10.1161/CIRCINTERVENTIONS.116.004497

14. Chen SL, Xu B, Han YL, et al. Clinical Outcome After DK Crush Versus Culotte Stenting of Distal Left Main Bifurcation Lesions: The 3-Year FollowUp Results of the DKCRUSH-III Study. JACC Cardiovasc Interv. 2015;8(10):1335-1342. doi:10.1016/j.jcin.2015.05.017

15. Chen X, Li X, Zhang JJ, et al. 3-Year Outcomes of the DKCRUSH-V Trial Comparing DK Crush With Provisional Stenting for Left Main Bifurcation Lesions. JACC Cardiovasc Interv. 2019;12(19):1927-1937. doi:10.1016/j.jcin.2019.04.056

16. Hildick-Smith D, Behan MW, Lassen JF, et al. The EBC TWO Study (European Bifurcation Coronary TWO): A Randomized Comparison of Provisional T-Stenting Versus a Systematic 2 Stent Culotte Strategy in Large Caliber True Bifurcations. Circ Cardiovasc Interv. 2016;9(9). doi:10.1161/CIRCINTERVENTIONS.115.003643

17. Kim YH, Lee JHJY, Roh JH, et al. Randomized comparisons between different stenting approaches for bifurcation coronary lesions with or without side branch stenosis. JACC Cardiovasc Interv. 2015;8(4):550-560. 
doi:10.1016/j.jcin.2015.01.016

18. Kervinen K, Niemelä M, Romppanen H, et al. Clinical outcome after crush versus culotte stenting of coronary artery bifurcation lesions: the Nordic Stent Technique Study 36-month follow-up results. JACC Cardiovasc Interv. 2013;6(11):1160-1165. doi:10.1016/j.jcin.2013.06.009

19. Pan M, de Lezo JS, Medina A, et al. Rapamycin-eluting stents for the treatment of bifurcated coronary lesions: a randomized comparison of a simple versus complex strategy. Am Heart J. 2004;148(5):857-864. doi:10.1016/j.ahj.2004.05.029

20. Ruiz-Salmerón RJ, Valenzuela LF, Pérez I, et al. Approach to Coronary Bifurcation Lesions Using the Everolimus-eluting Stent: Comparison Between a Simple Strategy and a Complex Strategy With T-stenting. Rev Española Cardiol (English Ed. 2013;66(8):636-643. doi:10.1016/j.rec.2013.03.005

21. Zheng XW, Zhao DH, Peng HY, et al. Randomized comparison of the crush versus the culotte stenting for coronary artery bifurcation lesions. Chin Med J (Engl). 2016;129(5):505-510. doi:10.4103/0366-6999.176997

22. Zhang L, Zhong W, Luo Y, Chen L. A pilot study on culottes versus crossover single stenting for true coronary bifurcation lesions. Acta Cardiol Sin. 2016;32(4):450-459. doi:10.6515/ACS20151112A

23. Ye F, Chen SL, Zhang JJ, et al. Hemodynamic changes of fractional flow reserve after double kissing crush and provisional stenting technique for true bifurcation lesions. Chin Med J (Engl). 2012;125(15):2658-2662. doi:10.3760/cma.j.issn.0366-6999.2012.15.003 
24. Chen S-L, Zhang Y, Xu B, et al. Five-year clinical follow-up of unprotected left main bifurcation lesion stenting: one-stent versus two-stent techniques versus double-kissing crush technique. EuroIntervention. 2012;8(7):803-814. doi:10.4244/EIJV8I7A123

25. Pavani M, Conrotto F, Cerrato E, et al. Long-Term Outcomes of Different Two-Stent Techniques With Second-Generation Drug-Eluting Stents for Unprotected Left Main Bifurcation Disease: Insights From the FAILS-2 Study. J Invasive Cardiol. 2018;30(8):276-281. http://www.ncbi.nlm.nih.gov/pubmed/30068784. Accessed April 23, 2020.

26. Fan L, Chen L, Luo Y, et al. DK mini-culotte stenting in the treatment of true coronary bifurcation lesions: a propensity score matching comparison with $\mathrm{T}$ provisional stenting. Heart Vessels. 2016;31(3):308-321. doi:10.1007/s00380$014-0611-7$

27. Freixa X, Almasood AA, Asif N, et al. Long-term outcomes using a two-stent technique for the treatment of coronary bifurcations. Int J Cardiol. 2013;168(1):446-451. doi:10.1016/j.ijcard.2012.09.130

28. Galassi AR, Tomasello SD, Capodanno D, Barrano G, Ussia GP, Tamburino C. Mini-crush versus T-provisional techniques in bifurcation lesions: clinical and angiographic long-term outcome after implantation of drug-eluting stents. JACC Cardiovasc Interv. 2009;2(3):185-194. doi:10.1016/j.jcin.2008.12.005

29. Ge L, Iakovou I, Cosgrave J, et al. Treatment of bifurcation lesions with two stents: one year angiographic and clinical follow up of crush versus $\mathrm{T}$ stenting. Heart. 2006;92(3):371-376. doi:10.1136/hrt.2005.061531

30. Palmerini T, Marzocchi A, Tamburino C, et al. Impact of bifurcation technique 
on 2-year clinical outcomes in 773 patients with distal unprotected left main coronary artery stenosis treated with drug-eluting stents. Circ Cardiovasc Interv. 2008;1(3):185-192. doi:10.1161/CIRCINTERVENTIONS.108.800631

31. Kanei Y, Nakra NC, Yili Huang, Fox JT. Long-term outcome of bifurcation stenting with drug-eluting stents. Angiology. 2010;61(7):633-637. doi:10.1177/0003319710369098

32. Kaplan S, Barlis P, Dimopoulos K, et al. Culotte versus T-stenting in bifurcation lesions: immediate clinical and angiographic results and midterm clinical follow-up. Am Heart J. 2007;154(2):336-343. doi:10.1016/j.ahj.2007.04.019

33. Migliorini A, Valenti R, Vergara R, et al. Angiographic and clinical outcome after crush of everolimus-eluting stent for distal unprotected left main disease. Catheter Cardiovasc Interv. 2017;90(1):72-77. doi:10.1002/ccd.26901

34. Kawamoto H, Takagi K, Chieffo A, et al. Long-term outcomes following minicrush versus culotte stenting for the treatment of unprotected left main disease: Insights from the milan and New-Tokyo (MITO) registry. Catheter Cardiovasc Interv. 2017;89(1):13-24. doi:10.1002/ccd.26654

35. Joy NG, Hedrington MS, Briscoe VJ, Tate DB, Ertl AC, Davis SN. Effects of acute hypoglycemia on inflammatory and pro-atherothrombotic biomarkers in individuals with type 1 diabetes and healthy individuals. Diabetes Care. 2010;33(7):1529-1535. doi:10.2337/dc09-0354

36. Razavi Nematollahi L, Kitabchi AE, Stentz FB, et al. Proinflammatory cytokines in response to insulin-induced hypoglycemic stress in healthy subjects. Metabolism. 2009;58(4):443-448. doi:10.1016/j.metabol.2008.10.018 
37. Dandona P, Chaudhuri A, Dhindsa S. Proinflammatory and prothrombotic effects of hypoglycemia. Diabetes Care. 2010;33(7):1686-1687. doi:10.2337/dc10-0503

38. Banning AP, Lassen JF, Burzotta F, et al. Percutaneous coronary intervention for obstructive bifurcation lesions: the 14th consensus document from the European Bifurcation Club. EuroIntervention. 2019;15(1):90-98. doi:10.4244/eij-d-19-00144

39. Ford TJ, McCartney P, Corcoran D, et al. Single- versus 2-stent strategies for coronary bifurcation lesions: A systematic review and meta-analysis of randomized trials with long-term follow-up. J Am Heart Assoc. 2018;7(11). doi:10.1161/JAHA.118.008730

40. Chen SL, Zhang JJ, Ye F, et al. Study comparing the double kissing (DK) crush with classical crush for the treatment of coronary bifurcation lesions: The DKCRUSH-1 Bifurcation Study with drug-eluting stents. Eur J Clin Invest. 2008;38(6):361-371. doi:10.1111/j.1365-2362.2008.01949.x

41. Chen S-L, Xu B, Han Y-L, et al. Clinical Outcome After DK Crush Versus Culotte Stenting of Distal Left Main Bifurcation Lesions: The 3-Year FollowUp Results of the DKCRUSH-III Study. JACC Cardiovasc Interv. 2015;8(10):1335-1342. doi:10.1016/j.jcin.2015.05.017

42. Chen S, Zhang J, Ye F, et al. Final kissing balloon inflation by classic crush stenting did not improve the clinical outcomes for the treatment of unprotected left main bifurcation lesions: The importance of double-kissing crush technique. Catheter Cardiovasc Interv. 2008;71(2):166-172. doi:10.1002/ccd.21317 
43. Di Gioia G, Sonck J, Ferenc M, et al. Clinical Outcomes Following Coronary Bifurcation PCI Techniques: A Systematic Review and Network MetaAnalysis Comprising 5,711 Patients. JACC Cardiovasc Interv. 2020;13(12):1432-1444. doi:10.1016/j.jcin.2020.03.054

44. Hildick-Smith D, de Belder AJ, Cooter N, et al. Randomized trial of simple versus complex drug-eluting stenting for bifurcation lesions: the British Bifurcation Coronary Study: old, new, and evolving strategies. Circulation. 2010;121(10):1235-1243. doi:10.1161/CIRCULATIONAHA.109.888297

45. Maeng M, Holm NR, Erglis A, et al. Long-term results after simple versus complex stenting of coronary artery bifurcation lesions: Nordic Bifurcation Study 5-year follow-up results. J Am Coll Cardiol. 2013;62(1):30-34. doi:10.1016/j.jacc.2013.04.015

46. Kumsars I, Holm NR, Niemelä M, et al. Randomised comparison of provisional side branch stenting versus a two-stent strategy for treatment of true coronary bifurcation lesions involving a large side branch: The NordicBaltic Bifurcation Study IV. Open Hear. 2020;7(1). doi:10.1136/openhrt-2018000947

47. Biondi-Zoccai G, Romagnoli E, Castagno D, et al. Simplifying clinical risk prediction for percutaneous coronary intervention of bifurcation lesions: The case for the ACEF (age, creatinine, ejection fraction) score. EuroIntervention. 2012;8(3):359-367. doi:10.4244/EIJV8I3A55

48. Yamawaki M, Terashita D, Takahashi H, et al. Impact of Diabetes Mellitus on Intravascular Ultrasound-Guided Provisional Stenting in Coronary Bifurcation Lesions J-REVERSE Sub-Study. J Interv Cardiol. 2016;29(6):576-587. 
doi:10.1111/joic.12353

49. Louvard Y, Thomas M, Dzavik V, et al. Classification of coronary artery bifurcation lesions and treatments: Time for a consensus! Catheter Cardiovasc Interv. 2008;71(2):175-183. doi:10.1002/ccd.21314

50. Seo J Bin, Shin DH, Park KW, et al. Predictors for Side Branch Failure During Provisional Strategy of Coronary Intervention for Bifurcation Lesions (from the Korean Bifurcation Registry). Am J Cardiol. 2016;118(6):797-803. doi:10.1016/j.amjcard.2016.06.049

51. Zimarino M, Barbato E, Nakamura S, et al. The impact of the extent of side branch disease on outcomes following bifurcation stenting. Catheter Cardiovasc Interv. 2020. doi:10.1002/ccd.28842

52. Perl L, Witberg G, Greenberg G, Vaknin-Assa H, Kornowski R, Assali A. Prognostic significance of the Medina classification in bifurcation lesion percutaneous coronary intervention with second-generation drug-eluting stents. Heart Vessels. 2020;35(3):331-339. doi:10.1007/s00380-019-01504-z

53. Nallamothu BK, Spertus JA, Lansky AJ, et al. Comparison of clinical interpretation with visual assessment and quantitative coronary angiography in patients undergoing percutaneous coronary intervention in contemporary practice: The assessing angiography (A2) project. Circulation. 2013;127(17):1793-1800. doi:10.1161/CIRCULATIONAHA.113.001952

54. Buccheri S, Franchina G, Romano S, et al. Clinical Outcomes Following Intravascular Imaging-Guided Versus Coronary Angiography-Guided Percutaneous Coronary Intervention With Stent Implantation: A Systematic Review and Bayesian Network Meta-Analysis of 31 Studies and 17,882 
Patients. JACC Cardiovasc Interv. 2017;10(24):2488-2498.

doi:10.1016/j.jcin.2017.08.051

55. Zhang J, Gao X, Kan J, et al. Intravascular Ultrasound Versus AngiographyGuided Drug-Eluting Stent Implantation: The ULTIMATE Trial. J Am Coll Cardiol. 2018;72(24):3126-3137. doi:10.1016/j.jacc.2018.09.013

56. Onuma Y, Katagiri Y, Burzotta F, et al. Joint consensus on the use of OCT in coronary bifurcation lesions by the European and Japanese bifurcation clubs. EuroIntervention. 2019;14(15):e1568-e1577. doi:10.4244/eij-d-18-00391

57. Mintz GS, Lefèvre T, Lassen JF, et al. Intravascular ultrasound in the evaluation and treatment of left main coronary artery disease: a consensus statement from the European Bifurcation Club. EuroIntervention. 2018;14(4):e467-e474. doi:10.4244/eij-d-18-00194

58. Xu B, Redfors B, Yang Y, et al. Impact of Operator Experience and Volume on Outcomes After Left Main Coronary Artery Percutaneous Coronary Intervention. JACC Cardiovasc Interv. 2016;9(20):2086-2093. doi:10.1016/j.jcin.2016.08.011

59. Konigstein M, Srdanovic I, Gore AK, et al. Outcomes of the Tryton-dedicated bifurcation stent for the treatment of true coronary bifurcations: Individualpatient-data pooled analysis. Catheter Cardiovasc Interv. 2019;93(7):12551261. doi:10.1002/ccd.27952

60. Gil RJ, Kern A, Pawłowski T, Bil J. Twelve-month clinical results from the new cobalt-chromium sirolimus-eluting dedicated bifurcation stent BiOSS LIM C Registry. Arch Med Sci. 2020. doi:10.5114/aoms.2020.92974 
61. Dedicated Bifurcation Stents for Coronary Bifurcation Lesions: A Systematic Review and Meta-Analysis of Randomized-Controlled Trials - PubMed. https://pubmed.ncbi.nlm.nih.gov/31786525/. Accessed January 18, 2021.

62. Uchida Y, Wagatsuma K, Yamazaki J. Treatment of non-left main bifurcation lesions using the sirolimus-eluting stent: A comparison of chronic outcomes of cross-over single stenting and crush stenting. J Cardiol. 2010;55(2):180-188. doi:10.1016/j.jjcc.2009.10.005

63. Ohya M, Morimoto T, Kubo S, et al. Two-year outcomes and predictors of target lesion revascularization for non-left main coronary bifurcation lesions following two-stent strategy with 2nd-generation drug-eluting stents. Circ J. 2018;82(3):798-806. doi:10.1253/circj.CJ-17-1092

64. Colombo A, Moses JW, Morice MC, et al. Randomized Study to Evaluate Sirolimus-Eluting Stents Implanted at Coronary Bifurcation Lesions. Circulation. 2004;109(10):1244-1249. doi:10.1161/01.CIR.0000118474.71662.E3 
Figure 1. Flow chart showing the process of selecting studies to the meta-analysis.

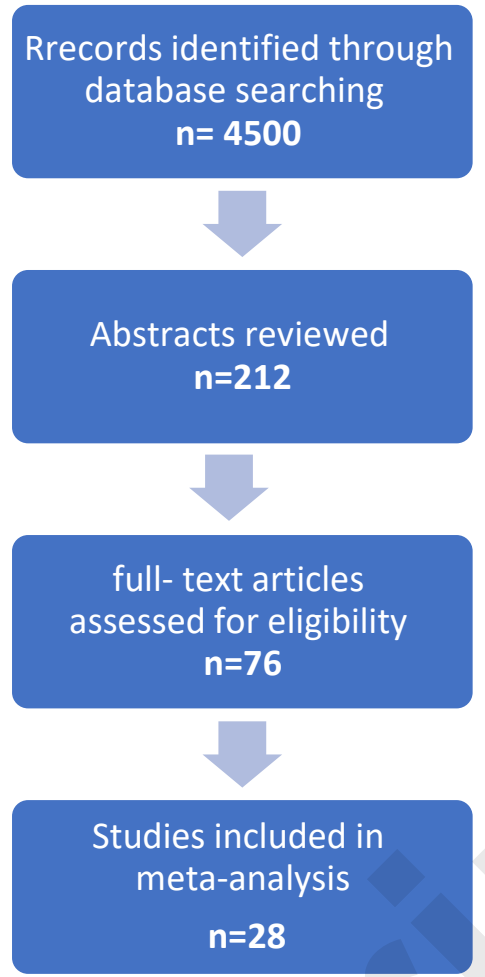


Figure 3. Network diagram with (A) and without (B) combining double-kissing crush technique with other crush techniques.

A

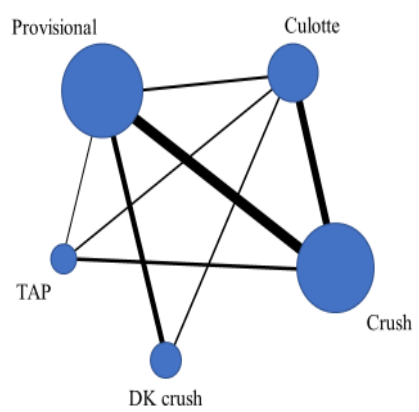

B

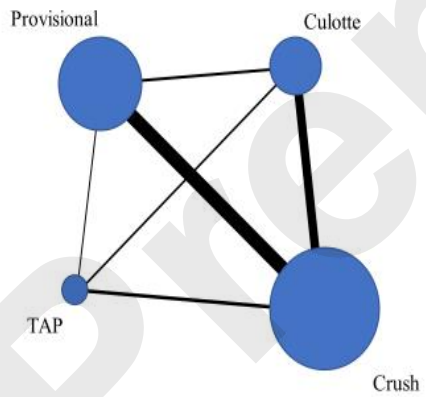


Figure 2. Representativeness of each bifurcation stenting technique in the included studies.

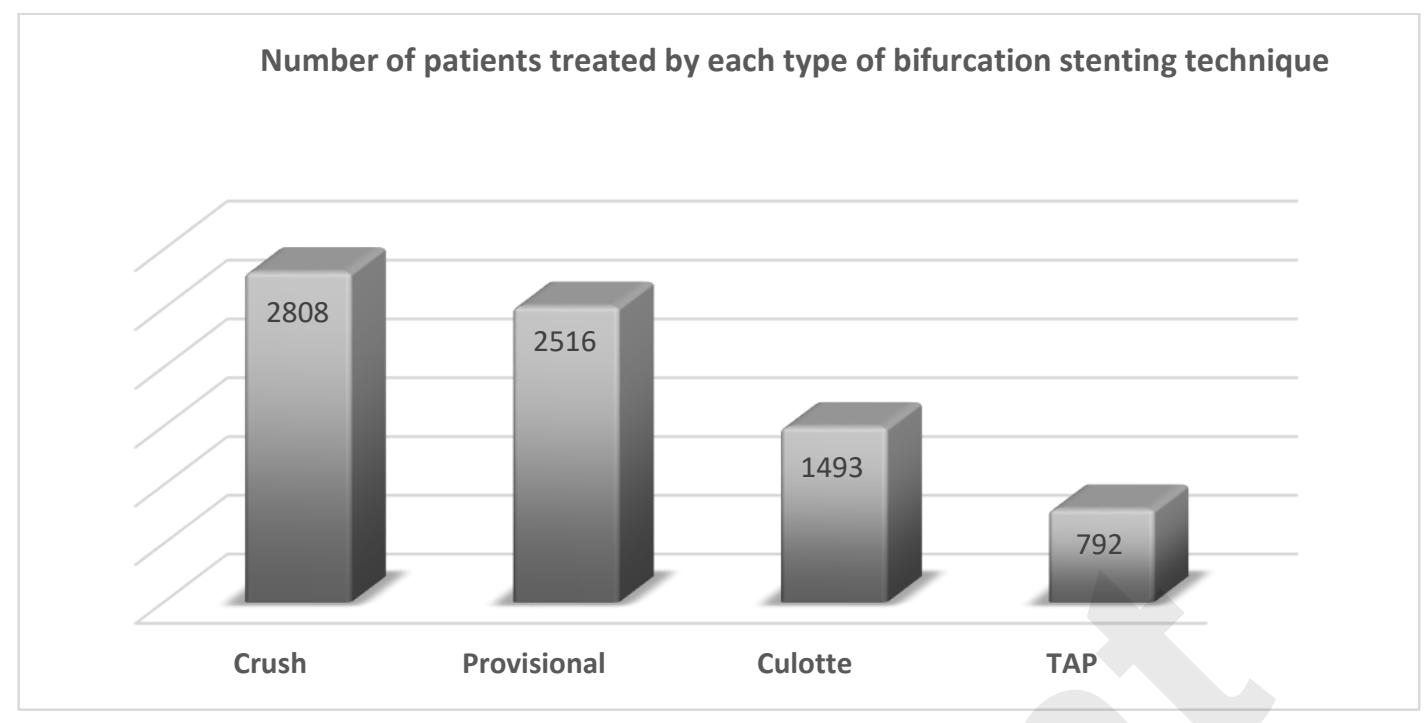


Table 1. Study characteristics.

\begin{tabular}{|c|c|c|c|c|c|c|}
\hline Study & Left Main & $\begin{array}{c}\text { Year of } \\
\text { publication }\end{array}$ & Follow-up time & Design & $\begin{array}{c}\text { Cohort } \\
\text { size }\end{array}$ & Groups (n) \\
\hline BBK II $^{10}$ & both & 2016 & 12 & RCT & 300 & $\begin{array}{l}\text { TAP } 150 \\
\text { culotte } 150\end{array}$ \\
\hline BBK I ${ }^{11}$ & non LM & 2015 & 60 & RCT & 202 & $\begin{array}{l}\text { TAP } 101 \\
\text { Provisional } 101\end{array}$ \\
\hline CACTUS $^{16}$ & non LM & 2008 & 6 & RCT & 350 & $\begin{array}{l}\text { Crash } 177 \\
\text { Provisional } 173\end{array}$ \\
\hline DKCRUSH II $^{17}$ & both & 2017 & 60 & RCT & 366 & $\begin{array}{l}\text { Crush } 183 \\
\text { Provisional } 183\end{array}$ \\
\hline DKCRUSH III $^{18}$ & LM & 2015 & 36 & RCT & 419 & $\begin{array}{l}\text { Crush } 210 \\
\text { Culotte } 209\end{array}$ \\
\hline DKCRUSH V ${ }^{34}$ & LM & 2019 & 36 & RCT & 482 & $\begin{array}{l}\text { Crush } 240 \\
\text { Provisional } 242\end{array}$ \\
\hline $\mathrm{EBC} \mathrm{II}^{20}$ & Non LM & 2016 & 12 & RCT & 200 & $\begin{array}{l}\text { Culotte } 97 \\
\text { Provisional } 103\end{array}$ \\
\hline $\mathrm{Kim}^{21}$ & Non LM & 2015 & 12 & RCT & 419 & $\begin{array}{l}\text { Crush } 213 \\
\text { Provisional } 206\end{array}$ \\
\hline Nordic II ${ }^{22}$ & Both & 2013 & 36 & RCT & 424 & $\begin{array}{l}\text { Crush } 209 \\
\text { Culotte } 215\end{array}$ \\
\hline $\operatorname{Pan}^{23}$ & Non LM & 2004 & 6 & RCT & 91 & $\begin{array}{l}\text { TAP } 44 \\
\text { Provisional } 47\end{array}$ \\
\hline Ruiz-Salmeron $^{12}$ & Non LM & 2013 & 9 & RCT & 69 & $\begin{array}{l}\text { TAP } 36 \\
\text { Provisional } 33\end{array}$ \\
\hline Zheng $^{13}$ & Both & 2016 & 12 & RCT & 300 & $\begin{array}{l}\text { Crush } 150 \\
\text { Culotte } 150\end{array}$ \\
\hline Zhang $^{14}$ & Both & 2016 & 9 & RCT & 104 & $\begin{array}{l}\text { Culotte } 52 \\
\text { Provisional } 52\end{array}$ \\
\hline $\mathrm{Ye}^{15}$ & Both & 2012 & 12 & RCT & 68 & $\begin{array}{l}\text { Crush } 38 \\
\text { Provisional } 30\end{array}$ \\
\hline Chen $\mathrm{LM}^{24}$ & LM & 2012 & 60 & observational & 387 & $\begin{array}{l}\text { Crush } 155 \\
\text { Provisional } 232\end{array}$ \\
\hline FAILS $2^{25}$ & LM & 2018 & 31 & observational & 237 & $\begin{array}{l}\text { Crush } 103 \\
\text { TAP } 66 \\
\text { Culotte } 68 \\
\end{array}$ \\
\hline Fan $\mathrm{PSM}^{26}$ & Both & 2016 & 12 & observational & 132 & $\begin{array}{l}\text { Culotte } 66 \\
\text { Provisional } 66\end{array}$ \\
\hline Freixa $^{27}$ & Both & 2013 & 49.2 & observational & 360 & $\begin{array}{l}\text { Crush } 304 \\
\text { culotte } 56\end{array}$ \\
\hline Galassi $^{28}$ & Non LM & 2009 & 36 & observational & 457 & $\begin{array}{l}\text { Crush } 199 \\
\text { Provisional } 258\end{array}$ \\
\hline $\mathrm{Ge}^{29}$ & Non LM & 2006 & 12 & observational & 182 & $\begin{array}{l}\text { Crush } 121 \\
\text { TAP } 61\end{array}$ \\
\hline GISE SICI $^{30}$ & LM & 2008 & 24 & observational & 705 & $\begin{array}{l}\text { Provisional } 456 \\
\text { Crush } 121 \\
\text { TAP } 128\end{array}$ \\
\hline Kanei $^{31}$ & LM & 2010 & 22 & observational & 106 & $\begin{array}{l}\text { Crush } 64 \\
\text { TAP } 42\end{array}$ \\
\hline Kaplan $^{32}$ & Non LM & 2007 & 9 & observational & 80 & $\begin{array}{l}\text { Culotte } 45 \\
\text { TAP } 35\end{array}$ \\
\hline Migliorini $^{33}$ & LM & 2017 & 12 & observational & 405 & $\begin{array}{l}\text { Crush } 127 \\
\text { provisional } 278\end{array}$ \\
\hline $\mathrm{MITO}^{34}$ & LM & 2016 & 60 & observational & 225 & $\begin{array}{l}\text { Crush } 135 \\
\text { Culotte } 90\end{array}$ \\
\hline Uchida $^{59}$ & Non LM & 2009 & $8 \pm 4$ & observational & 92 & $\begin{array}{l}\text { Provisional } 33 \\
\text { Crush } 59\end{array}$ \\
\hline Ohya $^{60}$ & Non LM & 2018 & 24 & observational & 356 & $\begin{array}{l}\text { Culotte } 295 \\
\text { TAP } 69\end{array}$ \\
\hline Colombo $^{61}$ & Non LM & 2004 & 6 & observational* & 83 & $\begin{array}{l}\text { Provisional } 23 \\
\text { TAP } 60\end{array}$ \\
\hline
\end{tabular}

\section{LM=left main}

* Statistical analysis was performed as treated and not intention to treat (ITT) 
Table 2. Patients demographics and comorbidities.

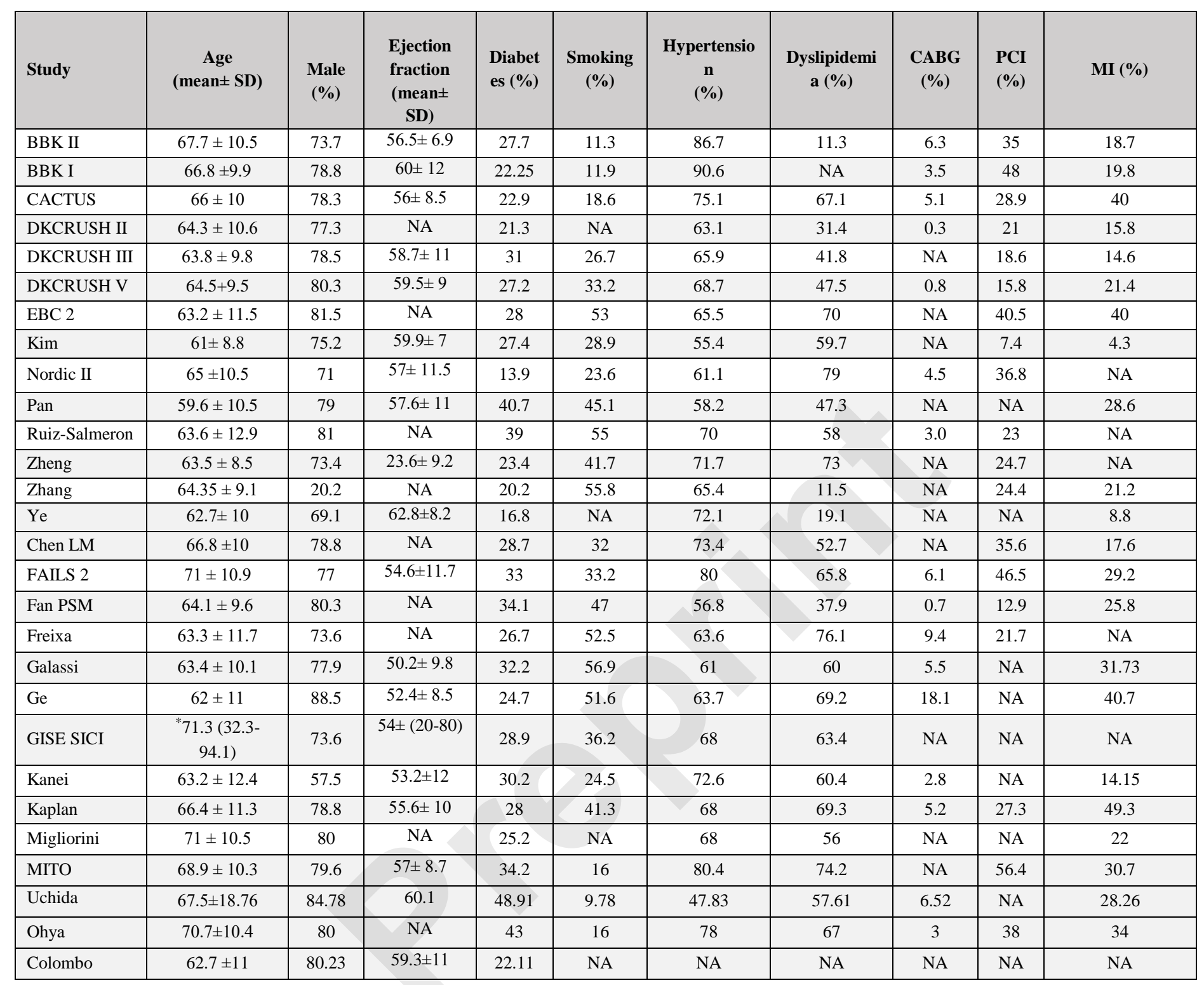

*reported median and inter quartile range (IQR)

$\mathrm{CABG}=$ coronary artery bypass graft, $\mathrm{PCI}=$ percutaneous coronary interventions, $\mathrm{MI}=$ myocardial infarction 
Table 3. Angiographic and procedural characteristics.

\begin{tabular}{|c|c|c|c|c|c|c|c|}
\hline Study & $\begin{array}{c}\text { Stent diameter- } \\
\text { MB (mm) }\end{array}$ & $\begin{array}{c}\text { Stent diameter } \\
-\mathrm{SB}(\mathrm{mm})\end{array}$ & $\begin{array}{l}\text { Main vessel } \\
\text { length of stent } \\
(\mathrm{mm})\end{array}$ & $\begin{array}{c}\text { Side branch } \\
\text { length of stent } \\
(\mathrm{mm})\end{array}$ & $\begin{array}{c}\text { True } \\
\text { bifurcation (\%) }\end{array}$ & $\begin{array}{c}\text { Use of final } \\
\text { kissing balloon } \\
\text { dilatation }(\%)\end{array}$ & $\begin{array}{c}\text { Use of IVUS / } \\
\text { OCT (\%) }\end{array}$ \\
\hline BBK II & NA & NA & NA & NA & 97 & 100 & NA \\
\hline BBK I & $3.2 \pm 0.48$ & $2.14 \pm 0.45$ & NA & NA & 68 & 100 & NA \\
\hline CACTUS & NA & NA & $23 . \pm 50.8$ & $18 \pm 5.6$ & 94 & 91.1 & $\begin{array}{l}\text { IVUS } \\
\text { MB } 3.7 \\
\text { SB } 2.6\end{array}$ \\
\hline DKCRUSH II & NA & NA & $28.7 \pm 13$ & $16.5 \pm 8.8$ & 100 & 89.3 & IVUS 47.3 \\
\hline DKCRUSH III & $3.37 \pm 0.37$ & $3.03 \pm 0.41$ & $34.6 \pm 15.03$ & $26.3 \pm 12.9$ & 100 & 99.5 & IVUS 71.4 \\
\hline DKCRUSH V & $3.26 \pm 0.37$ & $2.94 \pm 0.4$ & $48.7 \pm 18.5$ & $30.4 \pm 9.8$ & 100 & 89.2 & IVUS 41.7 \\
\hline EBC 2 & $3.04 \pm 0.32$ & $2.66 \pm 0.3$ & $23.2 \pm 4.95$ & $20.3 \pm 6.2$ & 100 & 95.1 & NA \\
\hline Kim & $3.3 \pm 0.3$ & $2.7 \pm 0.2$ & $37.1 \pm 15.1$ & $21.4 \pm 6.8$ & 87 & 87.6 & $\begin{array}{l}\text { IVUS } \\
\text { MB } 95.7 \\
\text { SB } 85.7\end{array}$ \\
\hline Nordic II & NA & NA & $23.6 \pm 9.2$ & $10.6 \pm 5.7$ & 78 & 88.5 & NA \\
\hline Pan & $2.9 \pm 03$ & $2.5 \pm 0.3$ & $25.5 \pm 10.7$ & NA & 100 & 68 & NA \\
\hline Ruiz-Salmeron & NA & NA & $24 \pm 11$ & NA & 87 & 54 & NA \\
\hline Zheng & NA & NA & $23.7 \pm 7.1$ & $10.3 \pm 5.7$ & 100 & 78.7 & NA \\
\hline Zhang & NA & NA & NA & NA & 100 & 43.8 & NA \\
\hline $\mathrm{Ye}$ & $3.12 \pm 0.36$ & $2.69 \pm 0.33$ & $32.26 \pm 14.1$ & $19.5 \pm 7.8$ & 100 & 94.1 & NA \\
\hline Chen LM & $3.38 \pm 0.41$ & & $29.2 \pm 13.5$ & NA & 95 & 62 & IVUS 16.3 \\
\hline FAILS 2 & $3.8 \pm 0.4$ & $3.2 \pm 0.6$ & $22.3 \pm 6.5$ & $19.3 \pm 5.8$ & 91 & 90.3 & $\begin{array}{l}\text { IVUS } 24.6 \\
\text { OCT } 3.7\end{array}$ \\
\hline Fan PSM & $3.0 \pm 0.39$ & $2.74 \pm 0.3$ & $36.4 \pm 15.8$ & $20.4 \pm 9.5$ & 100 & 94.7 & IVUS 9.1 \\
\hline Freixa & NA & NA & NA & NA & 90 & 82.5 & NA \\
\hline Galassi & $2.87 \pm 0.37$ & $2.54 \pm 0.3$ & $29.6 \pm 13.4$ & $18.4 \pm 7.5$ & 96 & 79.8 & NA \\
\hline $\mathrm{Ge}$ & NA & NA & $28.9 \pm 11.5$ & $23.2 \pm 9.3$ & NA & 63.4 & NA \\
\hline GISE SICI & NA & NA & NA & NA & NA & 42.3 & NA \\
\hline Kanei & $3.0 \pm 0.3$ & $2.7 \pm 0.3$ & $18.2 \pm 6.3$ & $12.5 \pm 4.8$ & 77 & 16 & NA \\
\hline Kaplan & $2.93 \pm 0.35$ & $2.57 \pm 0.3$ & $20.8 \pm 6$ & $16.6 \pm 5.9$ & 53 & 85 & NA \\
\hline Migliorini & $3.9 \pm 0.25$ & NA & $31 \pm 10.1$ & NA & 50 & 82 & IVUS 70 \\
\hline MITO & $3.4 \pm 0.2$ & $3.1 \pm 0.3$ & $23.8 \pm 6$ & $20.8 \pm 6.1$ & 89 & 98.2 & $\begin{array}{l}\text { IVUS } 67.6 \\
\text { OCT } 8.9\end{array}$ \\
\hline Uchida & $3 \pm 0.68$ & $2.62 \pm 0.64$ & $26.6 \pm 15.8$ & $19.8 \pm 11.4$ & 75 & 98 & IVUS 71 \\
\hline Ohya & NA & NA & $25.6 \pm 12.2$ & $17.8 \pm 9.1$ & 98 & 100 & IVUS 58 \\
\hline Colombo & NA & NA & NA & NA & 100 & 88.23 & IVUS 100 \\
\hline
\end{tabular}

$\mathrm{MB}$ = main branch, $\mathrm{SB}=$ side branch, IVUS = intravascular ultrasound, OCT = optical coherence tomography 

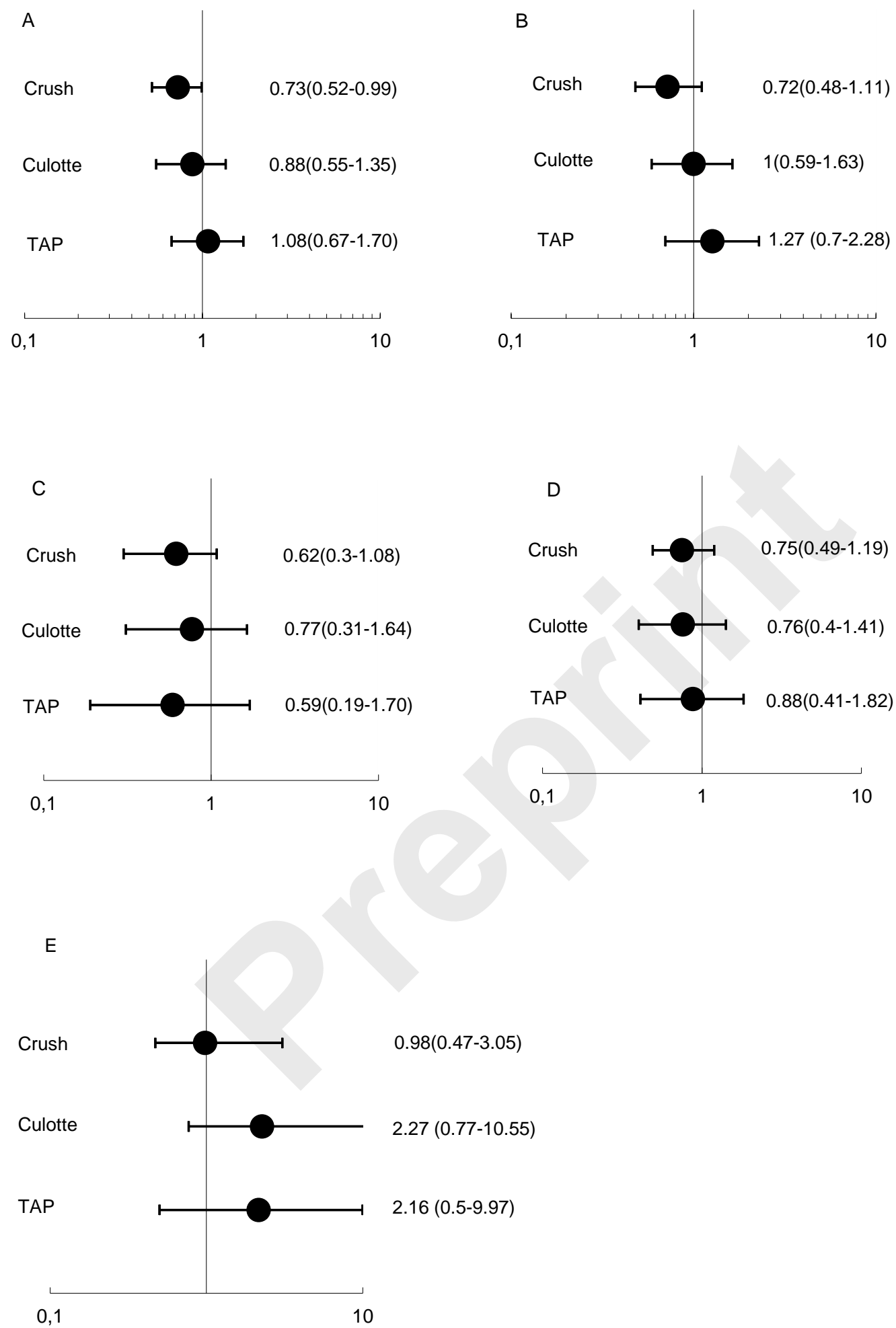

Figure 4. Forest plots of: (A) major adverse cardiac events, (B) target lesion revascularization, (C) myocardial infarction (D) all-cause mortality, and (E) stent thrombosis and between Crush, culotte and TAP techniques compared to provisional technique. 

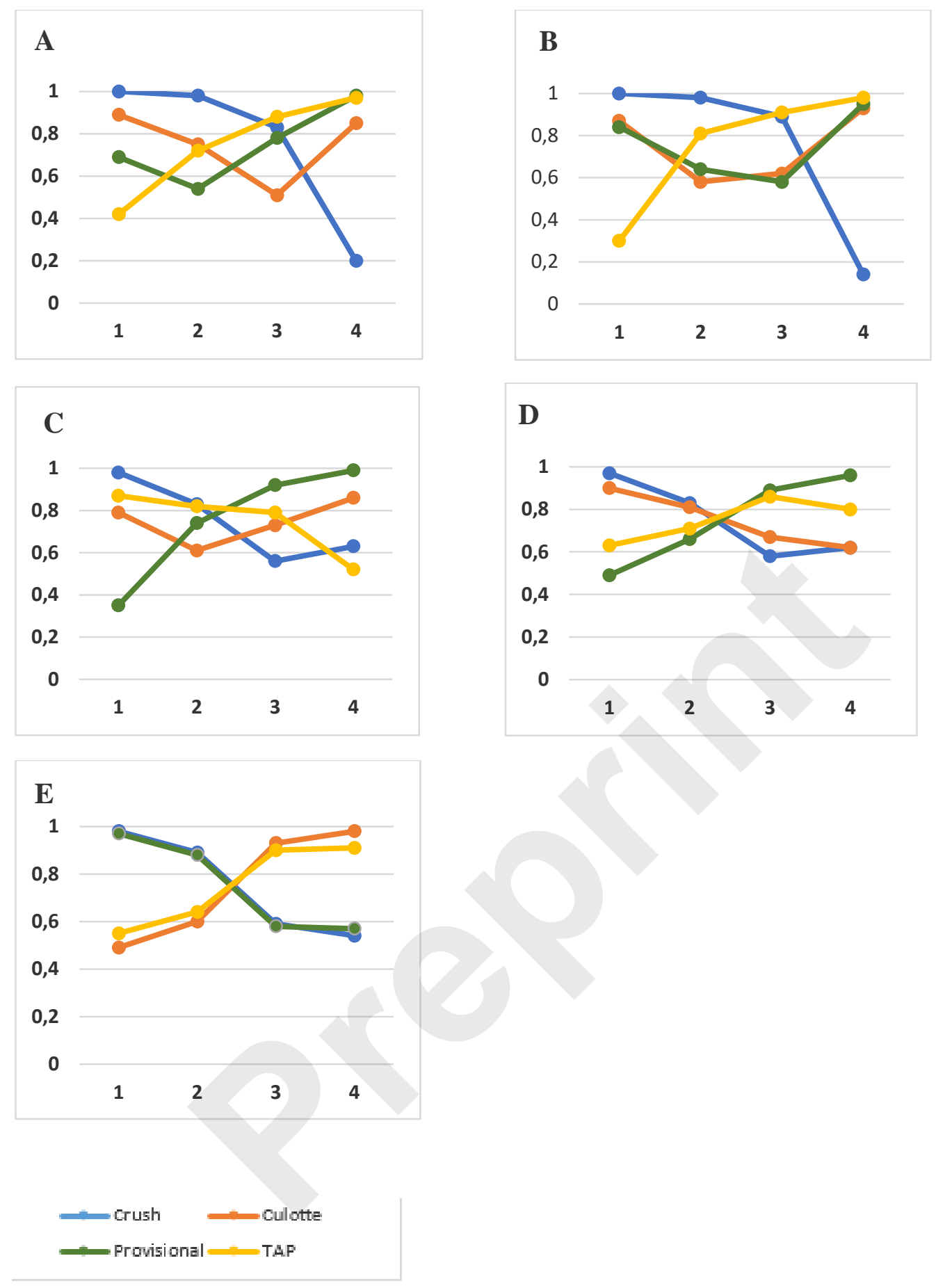

Figure 5. Ranking chart for the probability of the best, second, third and fourth treatment for: (A) major adverse cardiac events, (B) target lesion revascularization, (C) myocardial infarction (D) allcause mortality, and (E) stent thrombosis and between Crush, culotte and TAP techniques compared to provisional technique. 
B

A
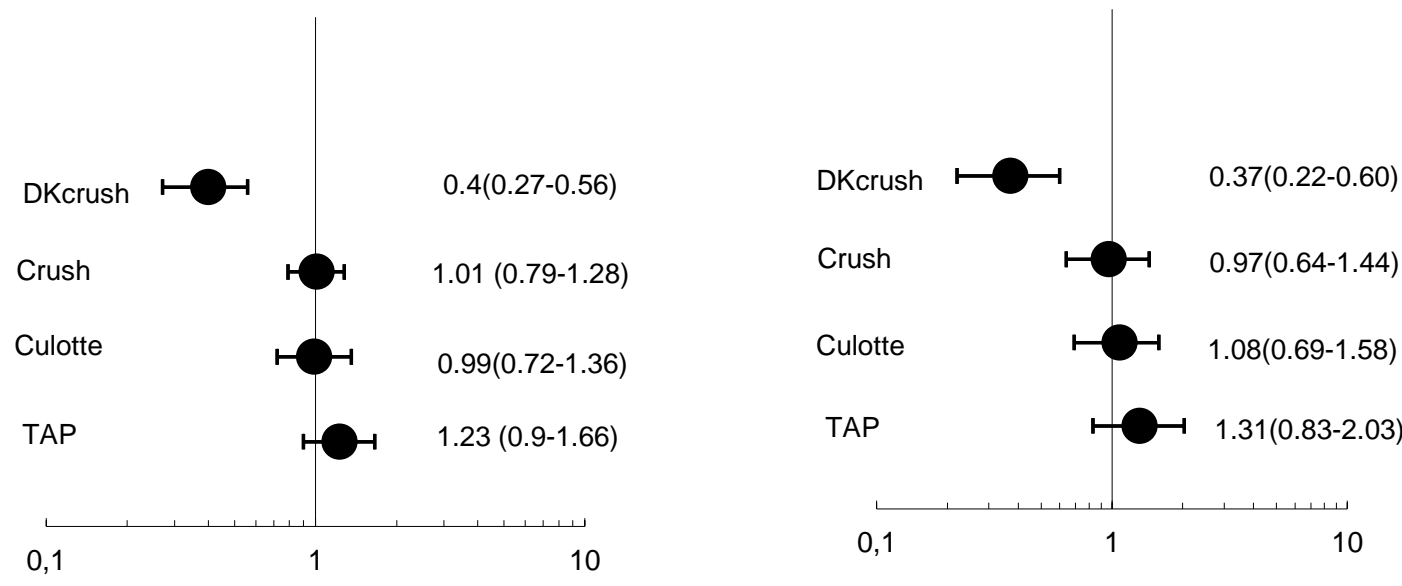

C
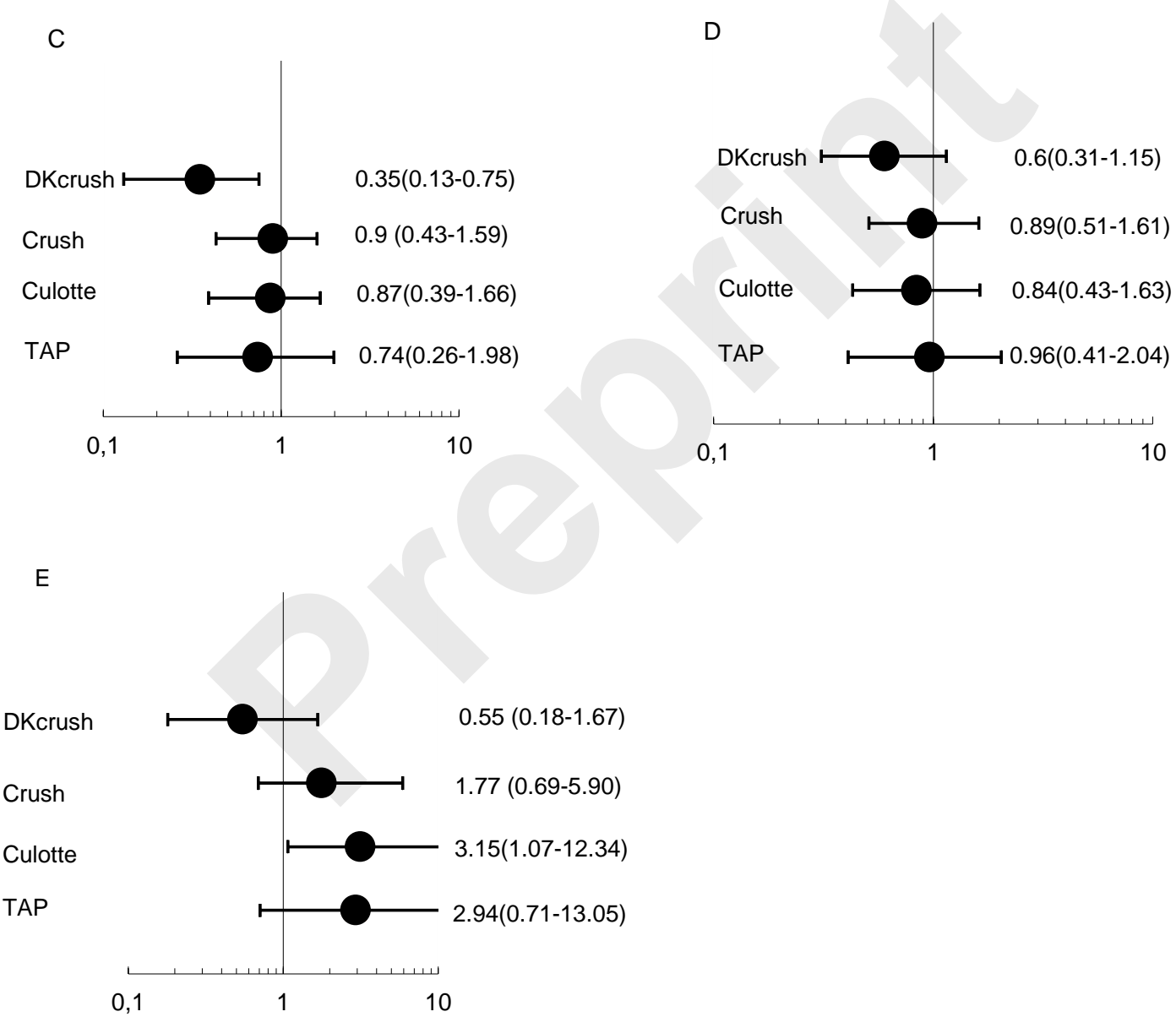

Figure 6. Forest plots of: (A) major adverse cardiac events, (B) target lesion revascularization, (C) myocardial infarction (D) all-cause mortality, and (E) stent thrombosis and between DKcrush, crush, culotte and TAP techniques compared to provisional technique. 

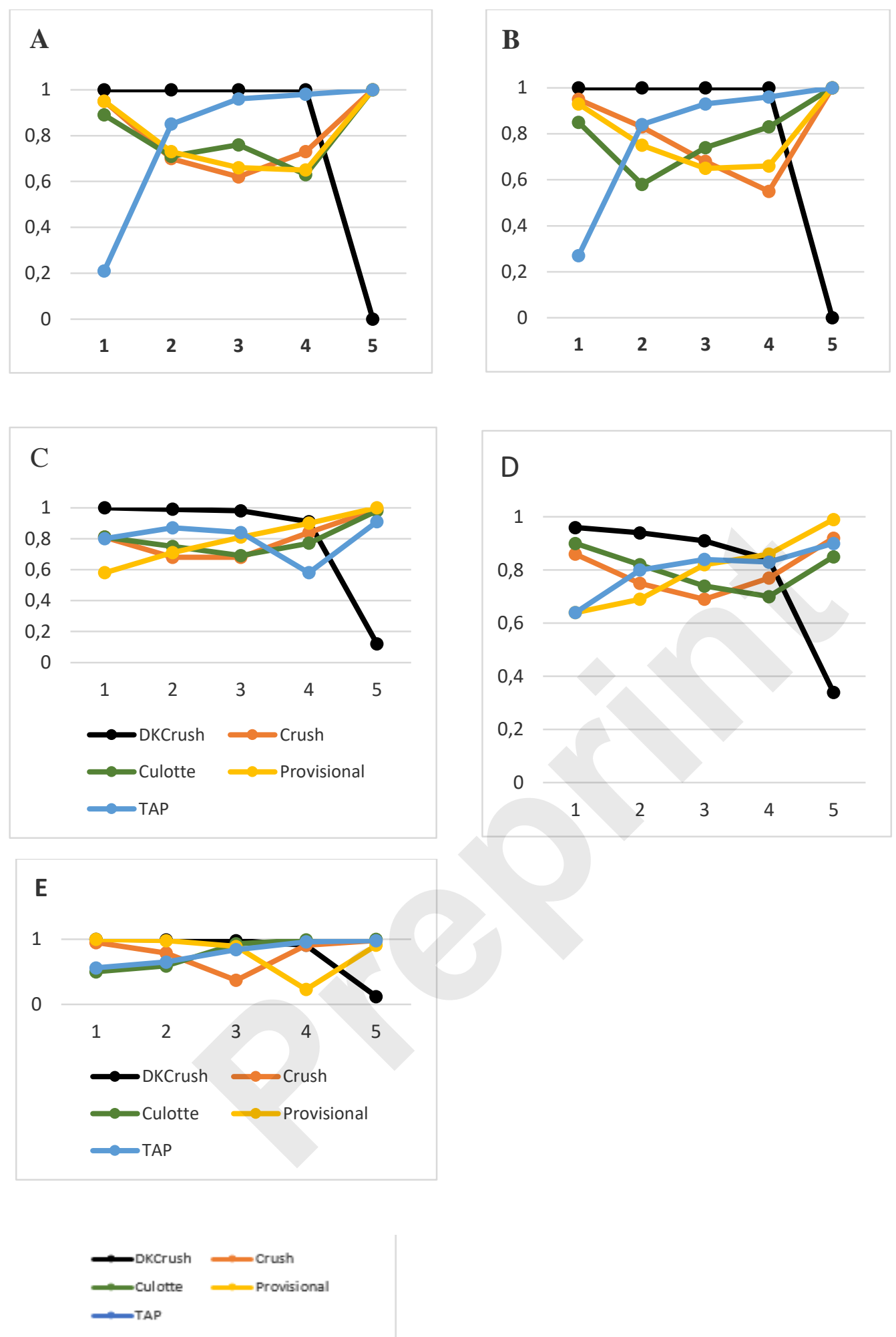

Figure 7. Ranking chart for the probability of best, second, third and fourth treatment for: (A) major adverse cardiac events, (B) target lesion revascularization, (C) myocardial infarction (D) all-cause mortality, and (E) stent thrombosis and between DKcrush, crush, culotte and TAP techniques compared to provisional technique. 


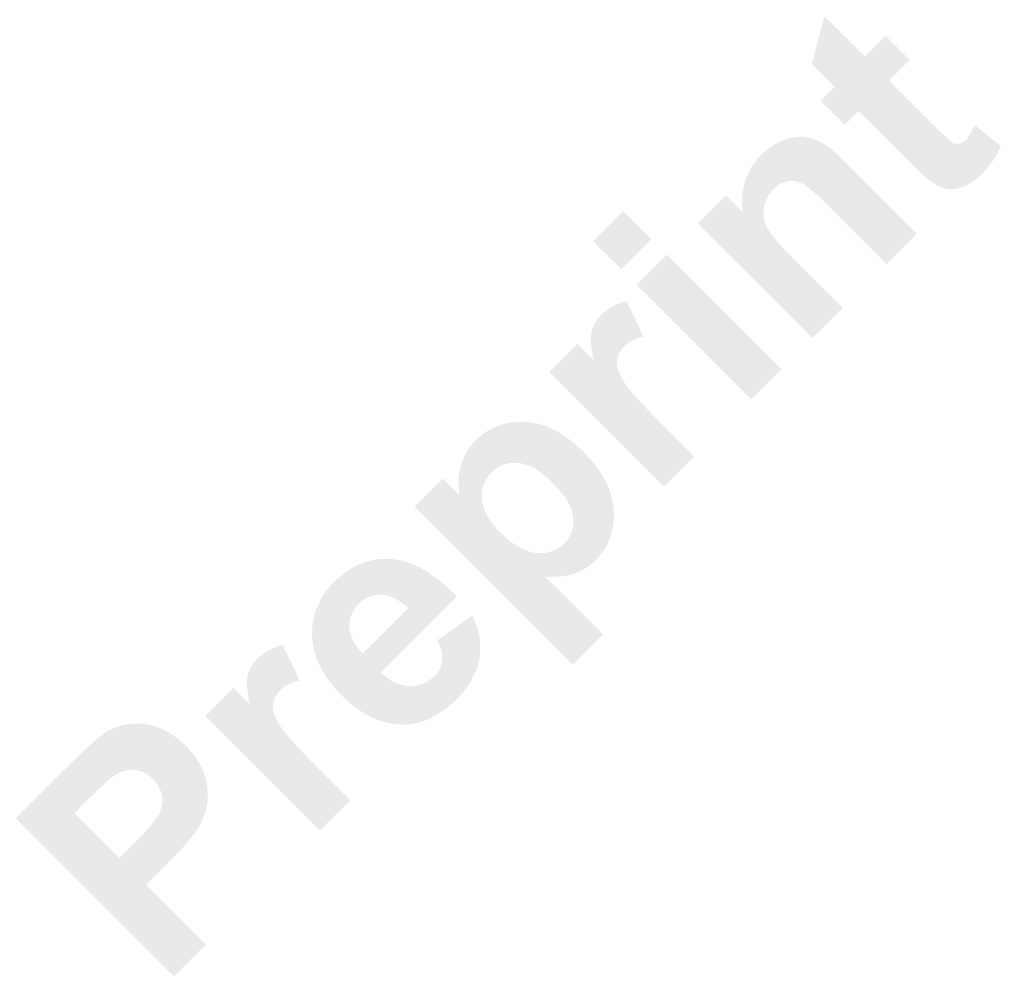




\section{Supplementary graphs}
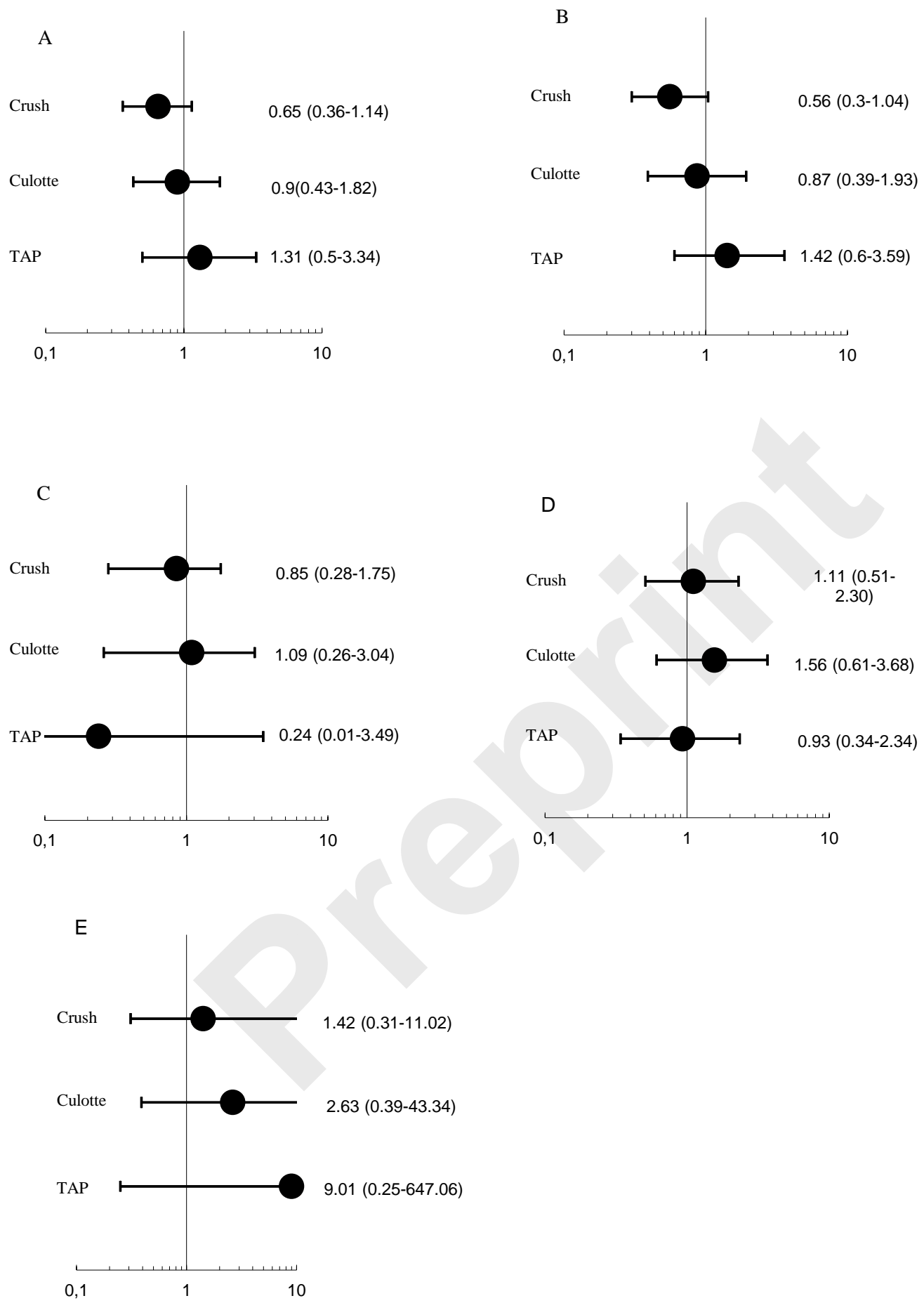

Figure 1. Forest plots of: (A) major adverse cardiac events, (B) target lesion revascularization, (C) myocardial infarction (D) all-cause mortality, and (E) stent thrombosis and between crush, culotte and TAP techniques compared to provisional technique in randomized controlled studies. 

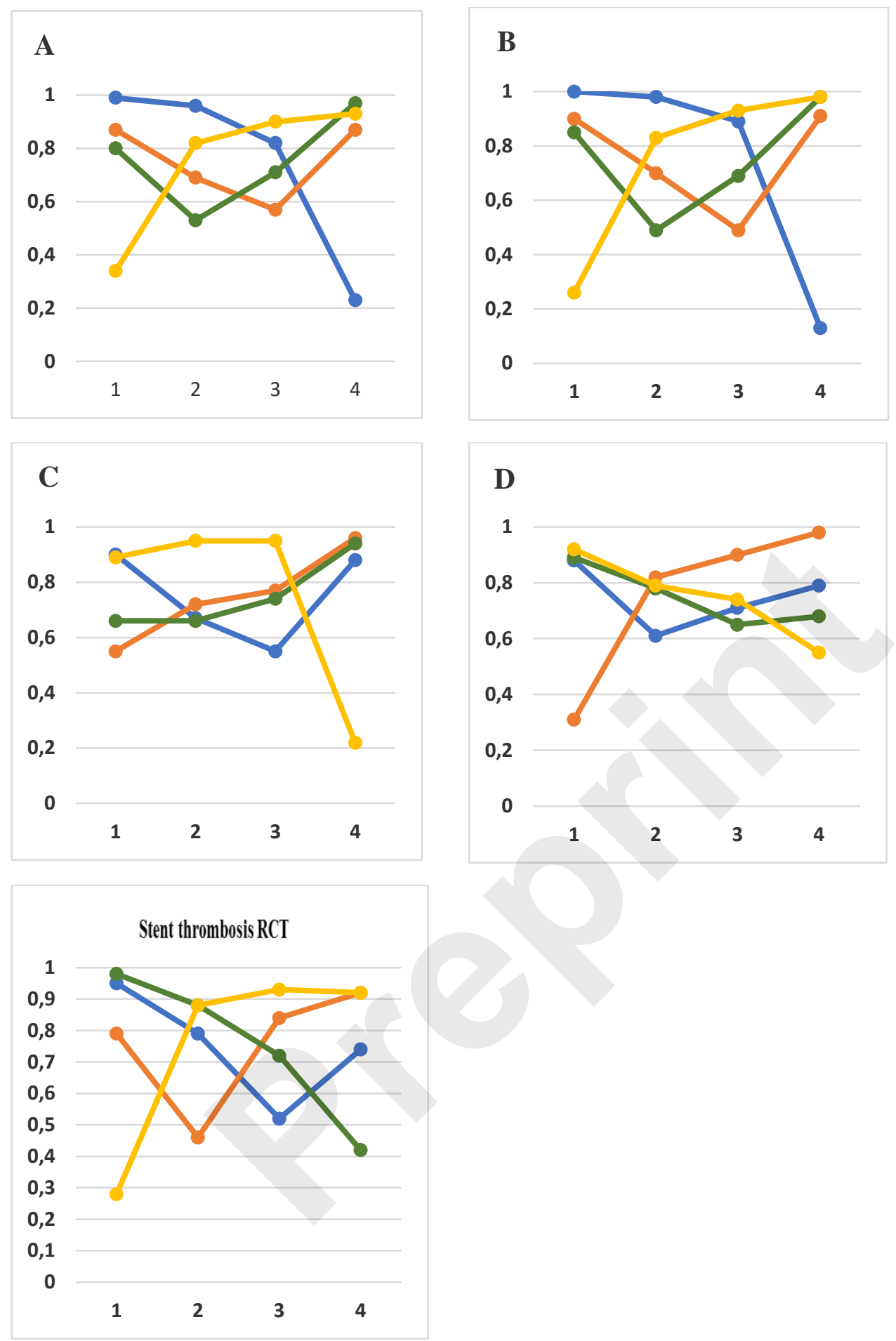

Figure 2. Ranking chart for the probability of best, second, third and fourth treatment for: (A) major adverse cardiac events, (B) target lesion revascularization, (C) myocardial infarction (D) all-cause mortality, and (E) stent thrombosis and between crush, culotte and TAP techniques compared to provisional technique in randomized controlled studies. 

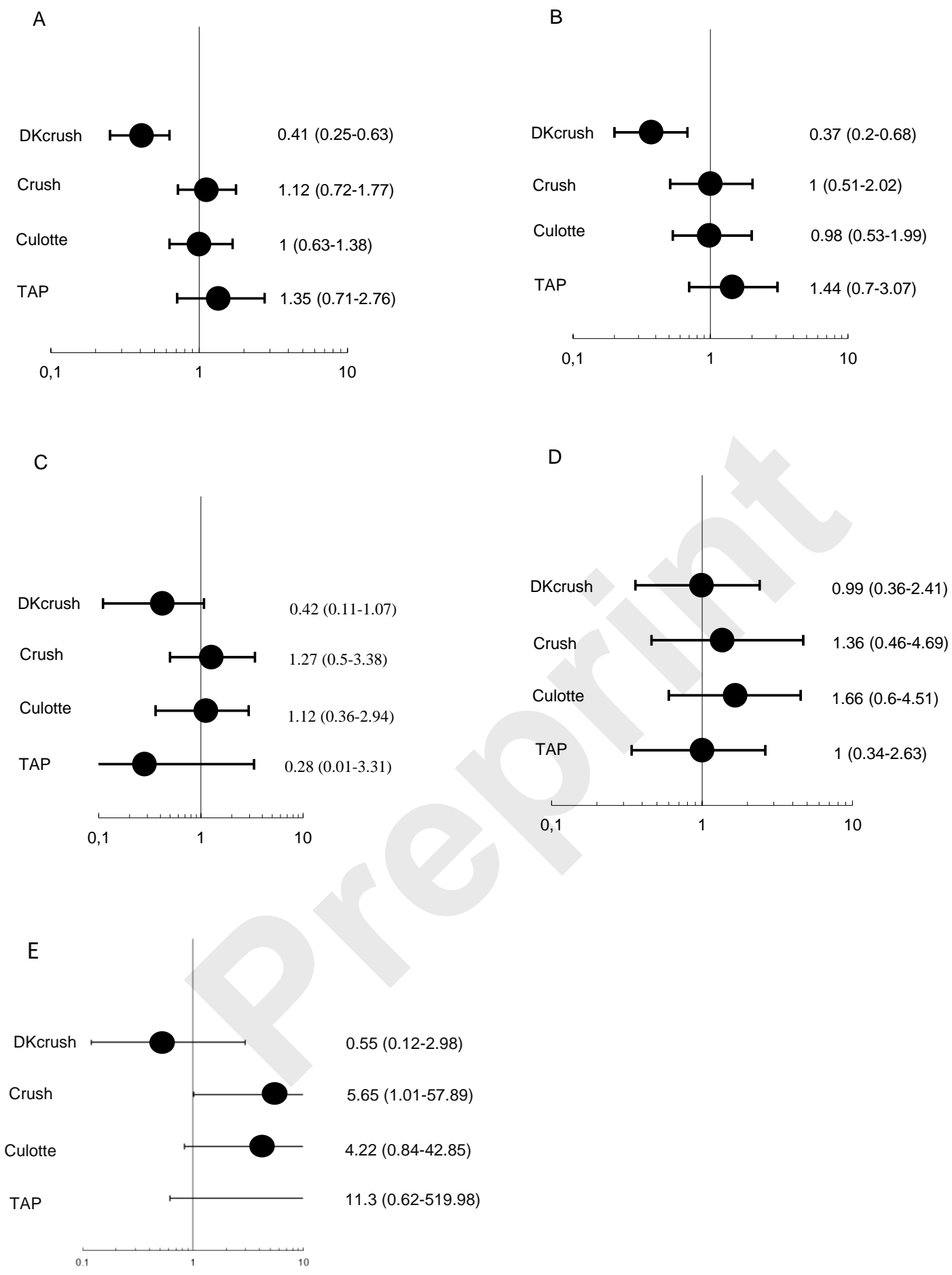

Figure 3. Forest plots of: (A) major adverse cardiac events, (B) target lesion revascularization, (C) myocardial infarction (D) all-cause mortality, and (E) stent thrombosis and between DKcrush, crush, culotte and TAP techniques compared to provisional technique in randomized controlled trials. 

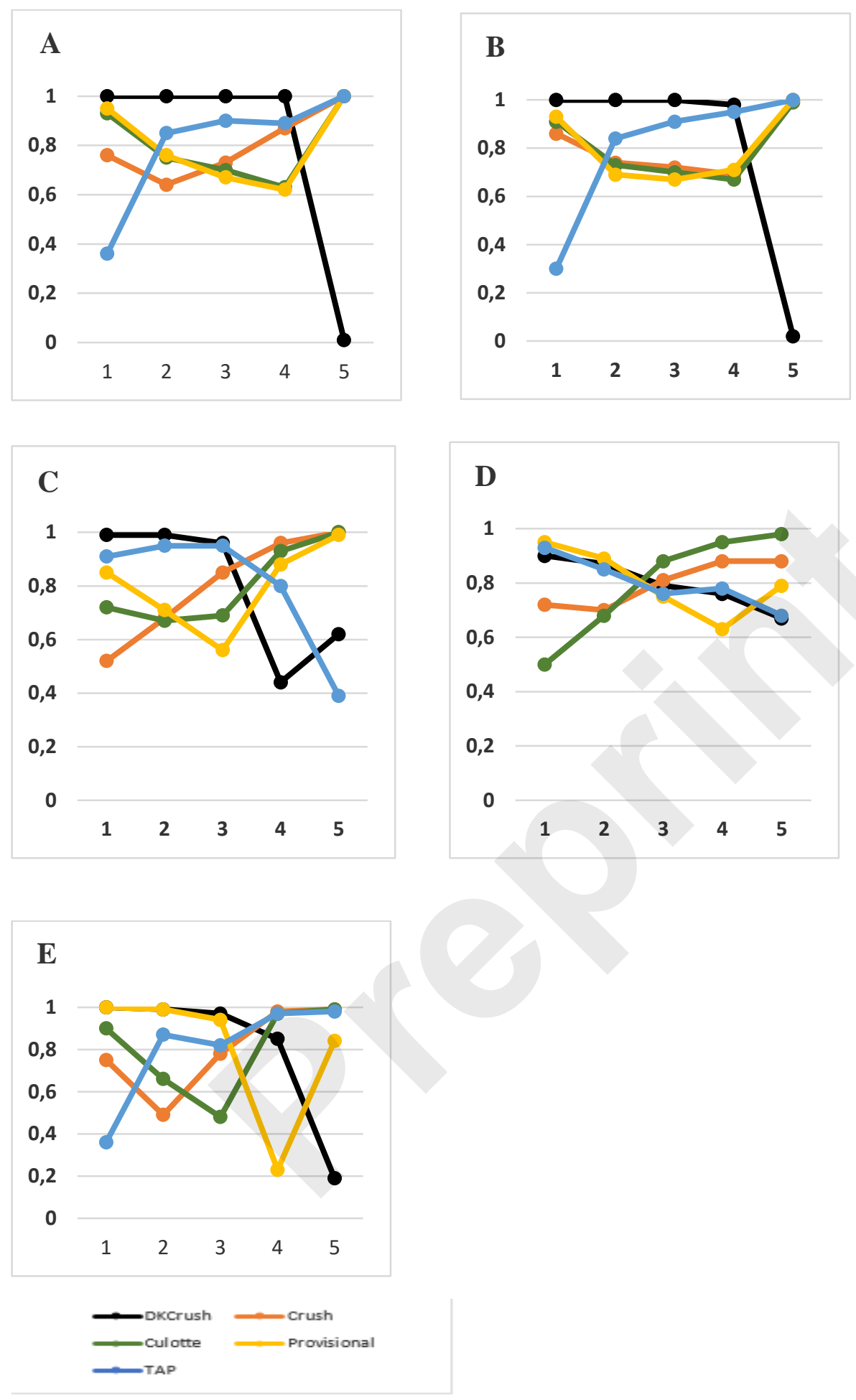

Figure 4. Ranking chart for the probability of best, second, third and fourth treatment for: (A) major adverse cardiac events, (B) target lesion revascularization, (C) myocardial infarction (D) all-cause mortality, and (E) stent thrombosis and between DKcrush, crush, culotte and TAP techniques compared to provisional technique in randomized controlled trials. 

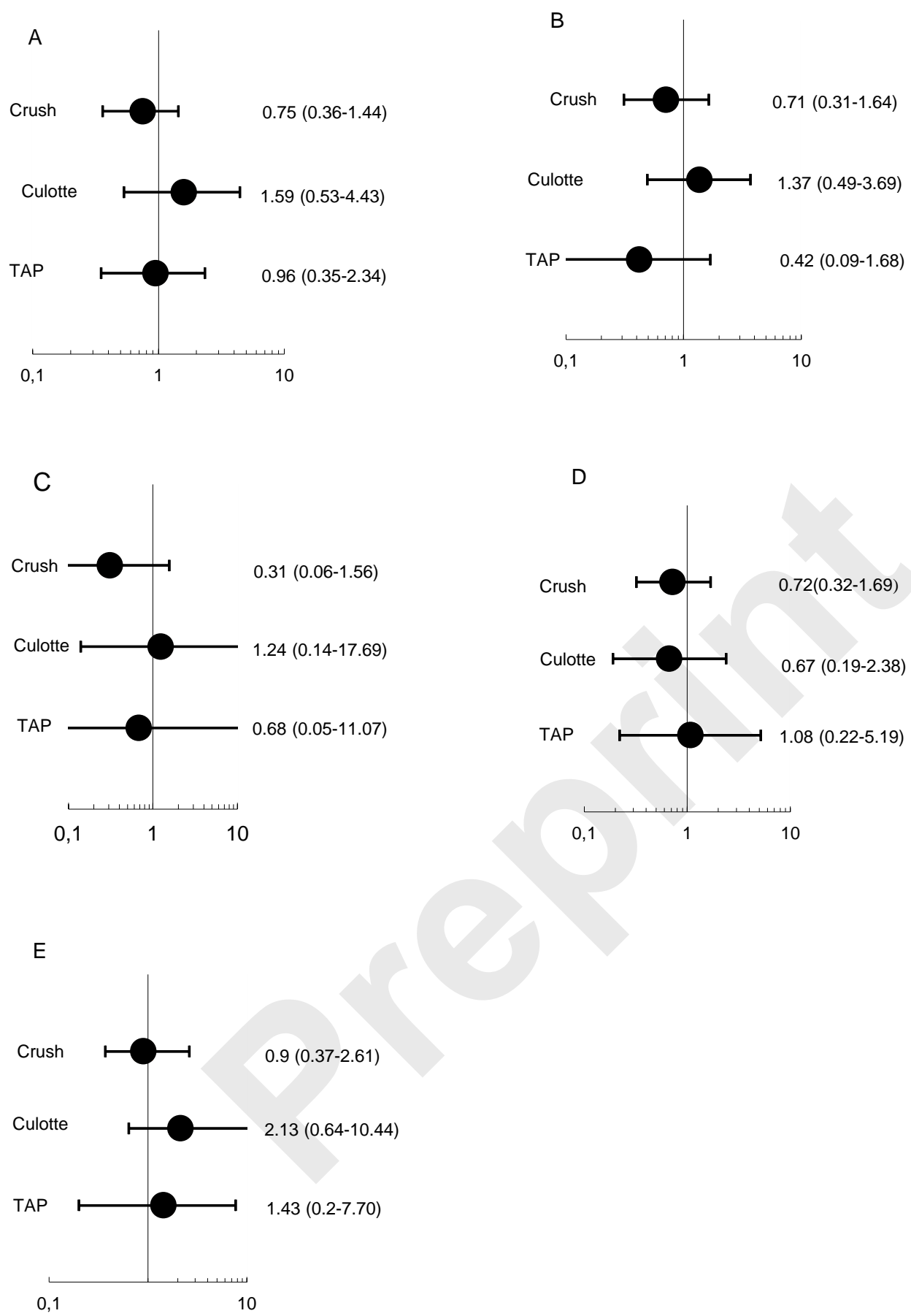

Figure 5. Forest plots of: (A) major adverse cardiac events, (B) target lesion revascularization, (C) myocardial infarction (D) all-cause mortality, and (E) stent thrombosis and between Crush, culotte and TAP techniques compared to provisional technique in treatment of left main disease. 

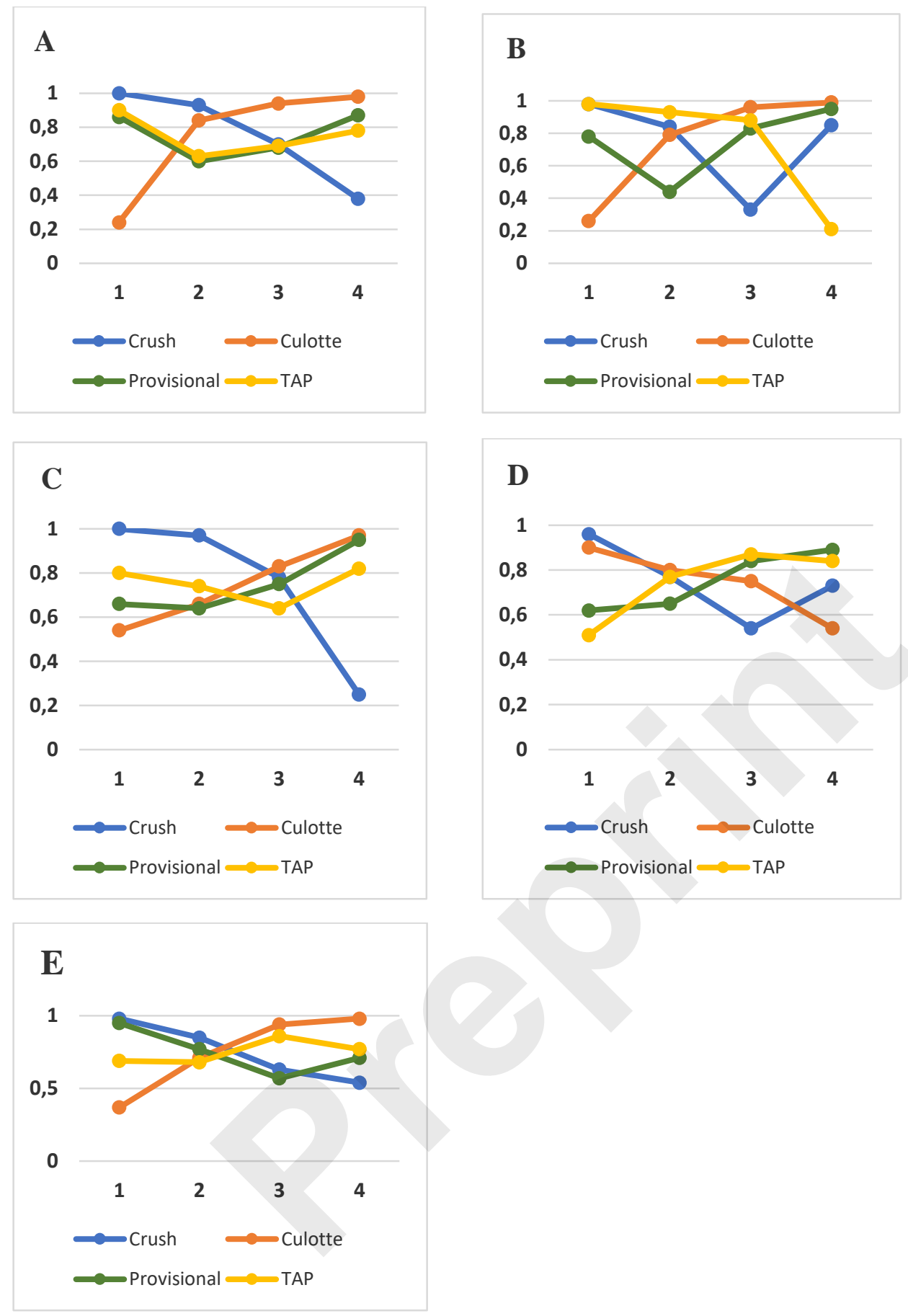

Figure 6. Ranking chart for the probability of best, second, third and fourth treatment for: (A) major adverse cardiac events, (B) target lesion revascularization, (C) myocardial infarction (D) allcause mortality, and (E) stent thrombosis and between Crush, culotte and TAP techniques compared to provisional technique in treatment of left main disease. 
B
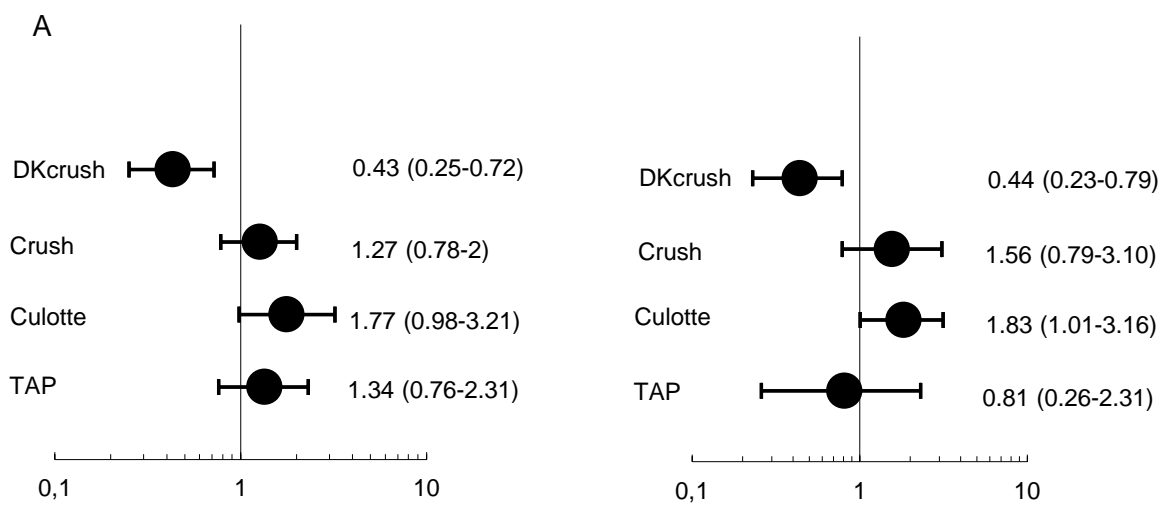

C

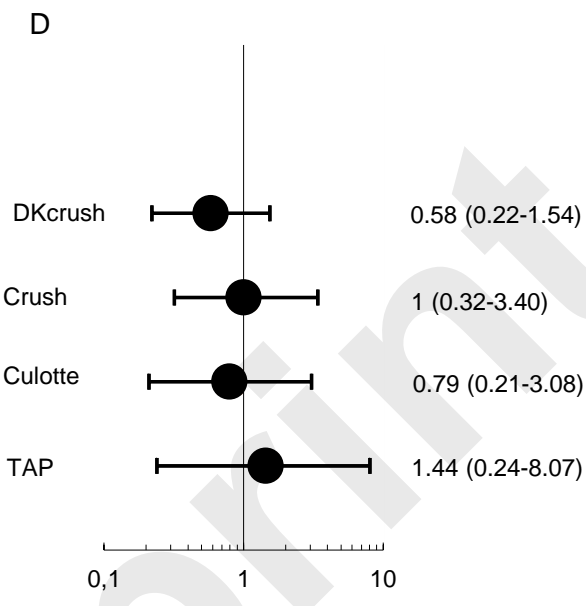

E

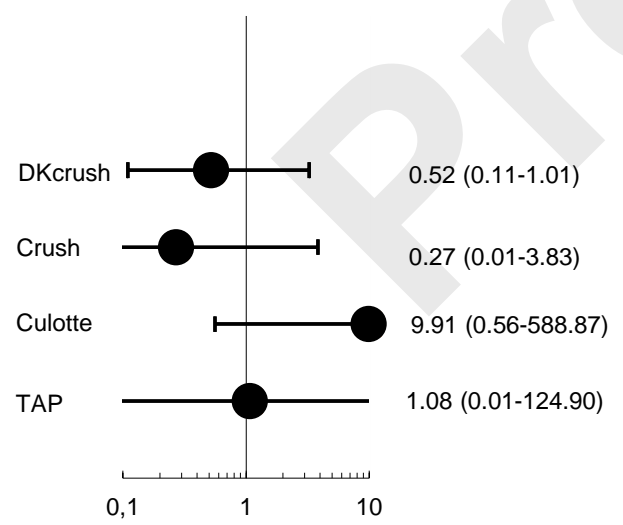

Figure 7. Forest plots of: (A) major adverse cardiac events, (B) target lesion revascularization, (C) myocardial infarction (D) all-cause mortality, and (E) stent thrombosis and between DKcrush, crush, culotte and TAP techniques compered to Provisional technique in treatment of left main disease. 

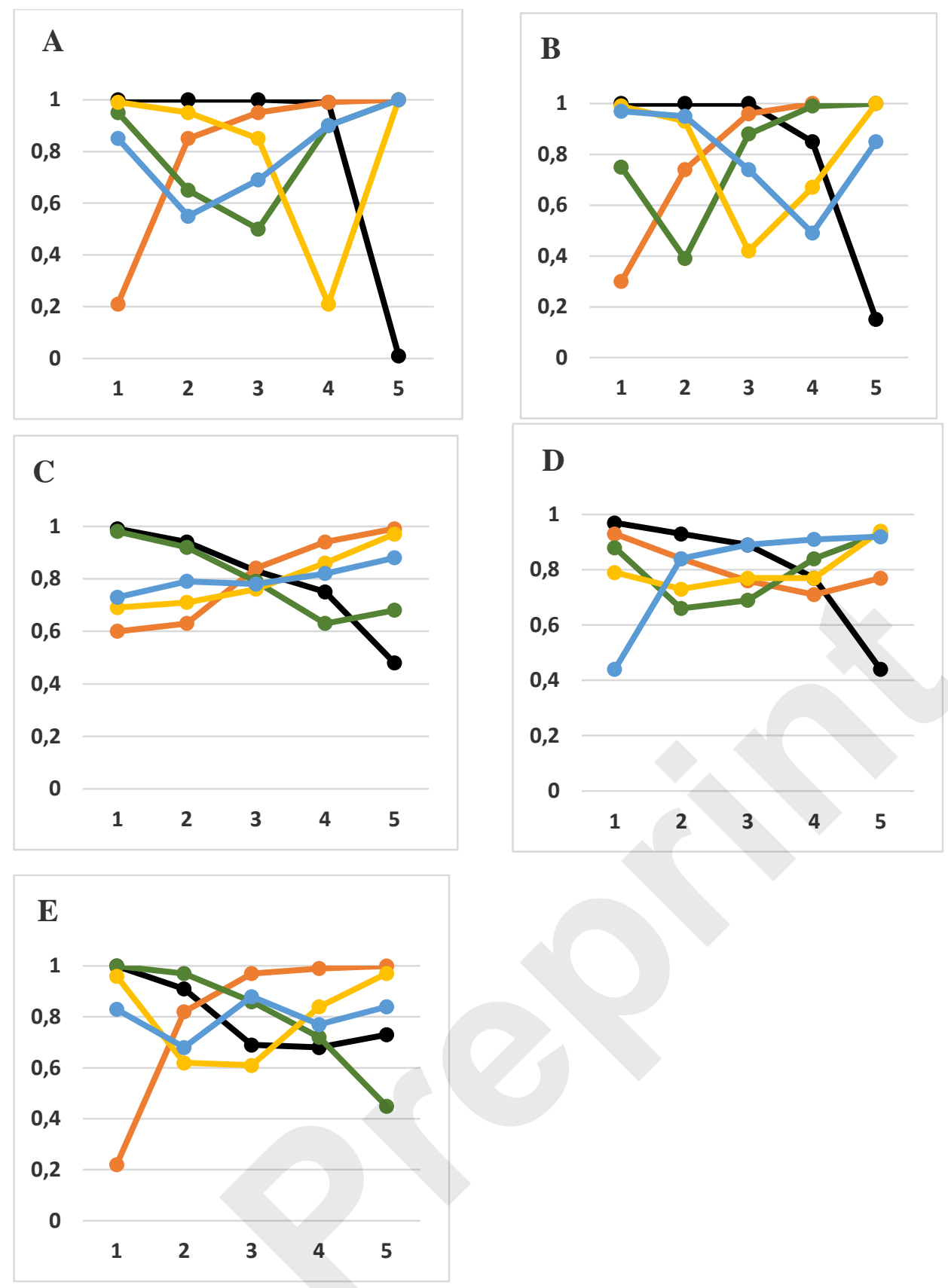

Figure 8. Ranking chart for the probability of best, second, third and fourth treatment for (A) major adverse cardiac events, (B) target lesion revascularization, (C) myocardial infarction (D) all-cause mortality, and (E) stent thrombosis and between DKcrush, crush, culotte and TAP techniques compered to Provisional technique in treatment of left main disease. 